Article

\title{
Dynamic Mechanical Analysis of Thermally Aged Fique Fabric-Reinforced Epoxy Composites
}

\author{
Michelle Souza Oliveira ${ }^{1}$, Fernanda Santos da Luz ${ }^{1}{ }^{(0}$, Fabio da Costa Garcia Filho ${ }^{2} \mathbb{D}$, Artur Camposo Pereira ${ }^{1}(\mathbb{D}$, \\ Vinícius de Oliveira Aguiar ${ }^{3}$, Henry Alonso Colorado Lopera ${ }^{4}$ and Sergio Neves Monteiro ${ }^{1, *}$ (i) \\ 1 Department of Materials Science, Military Institute of Engineering-IME, Rio de Janeiro 22290-270, Brazil; \\ oliveirasmichelle@ime.eb.br (M.S.O.); fernandaluz@ime.eb.br (F.S.d.L.); camposo@ime.eb.br (A.C.P.) \\ 2 Department of Mechanical and Aerospace Engineering, University of California San Diego-UCSD, \\ La Jolla, CA 92093, USA; fdacostagarciafilho@eng.ucsd.edu \\ 3 Department of Polymer Science and Technology, Institute of Macromolecules Professor Eloisa Mano-IMA, \\ Rio de Janeiro 21941-598, Brazil; nviny_815@hotmail.com \\ 4 CCComposites Laboratory, Universidad de Antioquia-UdeA, Calle 70 n 52-21, Medellin 050010, Colombia; \\ henry.colorado@udea.udea.edu.co \\ * Correspondence: sergio.neves@ime.eb.br
}

check for

updates

Citation: Oliveira, M.S.; da Luz, F.S.; da Costa Garcia Filho, F.;

Pereira, A.C.; de Oliveira Aguiar, V.;

Lopera, H.A.C.; Monteiro, S.N.

Dynamic Mechanical Analysis of

Thermally Aged Fique

Fabric-Reinforced Epoxy Composites.

Polymers 2021, 13, 4037. https://

doi.org/10.3390/polym13224037

Academic Editor: Emin Bayraktar

Received: 16 October 2021

Accepted: 13 November 2021

Published: 22 November 2021

Publisher's Note: MDPI stays neutral with regard to jurisdictional claims in published maps and institutional affiliations.

Copyright: (c) 2021 by the authors. Licensee MDPI, Basel, Switzerland. This article is an open access article distributed under the terms and conditions of the Creative Commons Attribution (CC BY) license (https:/ / creativecommons.org/licenses/by/ $4.0 /)$.
Abstract: Dynamic mechanical analysis (DMA) is one of the most common methods employed to study a material's viscoelastic properties. The effect of thermal aging on plain epoxy and a fique fabric-reinforced epoxy composite was investigated by comparing the mass loss, morphologies, and DMA properties of aged and unaged samples. In fact, thermal aging presents a big challenge for the high-temperature applications of natural fiber composites. In this work, both plain epoxy and fique fabric-reinforced epoxy composite were found to have different molecular mobility. This leads to distinct transition regions, with different changes in intensity caused by external loadings from time-aging. Three exponentially modified Gauss distribution functions (EMGs) were applied to loss factor curves of fique fabric-reinforced epoxy composite and plain epoxy, which allowed identifying three possible mobility ranges. From these results it was proposed that the thermal degradation behavior of natural fibers, especially fique fiber and their composites, might be assessed, based on their structural characteristics and mechanical properties.

Keywords: fique fabric; epoxy composite; DMA; accelerated aging; exponentially modified Gauss distribution

\section{Introduction}

One of the most common methods used to measure a material's viscoelastic properties is the dynamic mechanical analysis (DMA). Based on DMA it is possible to have information about the temperature- and time-dependent behavior [1,2], as well as aging [3-5], degradation [6], glass transition [7-9], degree of crosslinking [10-12], extent of phase mixing in blends [13,14], crystallinity [15], and interfacial adhesion [16-18], among others. Recently, the use of DMA as a characterization technique was applied to investigate mechanical properties of heterogeneous materials [19-22], spatial distribution of a material's properties [23], and crack healing [24].

The importance of the accelerated aging studies has been recognized as a research method, which serves the purpose of determining the usability conditions and period of a product [25]. Natural fiber-reinforced polymer composites (NFRPC), as any other product for technical application, undergo gradual degradation with the passing of time. The main reasons for aging in NFRPC are the operating conditions and the usage and storage procedures of these materials. The property changes' predictions of NFRPC are relevant to the security usage and reliability of the material $[26,27]$.

It has been discussed that reinforcement of natural fibers in the thermoplastics and thermoset matrices offers several benefits such as having low cost, being ecofriendly 
renewable, and causing less damage to processing equipment compared to synthetic reinforcements [28]. This discussion also addresses the fact that natural fibers present relatively lower mechanical properties due to inherently weaker adhesion to polymers' matrices when compared with synthetic fibers $[28,29]$. Other considerations for long-term sustainability and market acceptability of NFRPC include (1) energy and costs involved in the fiber supply chain; (2) a continuous and reliable source of natural fibers; (3) tax incentives for production; and (4) use in applications and (v) recycling [29,30].

The use of NFRPC is expected to grow in the future for specific applications, for example, use of light-weight natural fiber composites in ballistic armor [31-33]. In this case, thermal aging might play an important role in the armor expiration time. Indeed, aging affects the molecular mobility in both polymer matrix and natural fiber, which could accelerate the composite degradation under combined conditions of time and temperature [8].

Among the lesser known natural fibers that have been investigated as reinforcement of polymer composites stands the fique fiber extracted from the South American plant Furcraea andina [34-36]. In particular, textiles made of fique fiber, as illustrated in Figure 1, were found to be a promising reinforcement for polymer matrix composites $[20,22,37]$.

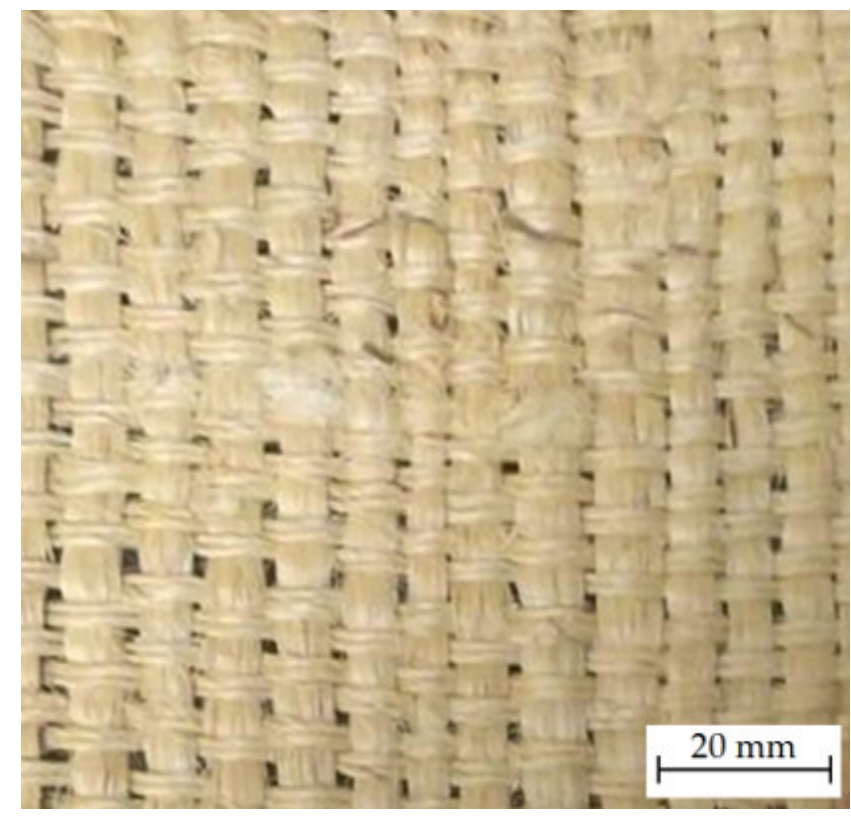

Figure 1. Fique fabric plain woven.

A recent investigation disclosed the superior ballistic performance of fique fabric as personal armor in comparison to worldwide-used synthetic aramid fabric [38-40]. A previous report on DMA results of polyester composites reinforced with up to $30 \mathrm{vol} \%$ of fique fabric [22] revealed a rise in viscoelastic stiffness and less mobility of the polyester chains. Moreover, a high attenuation of internal vibration and an increase in the glass transition temperature occurred with increasing the amount of fique fabric composites with up to $50 \mathrm{vol} \%$ of fique fabric [20], disclosing not only a superior ballistic performance compared to Kevlar ${ }^{\mathrm{TM}}$ but also economic and environmental advantages [39].

However, for successful application of these composites as ballistic armor their change under aging at a limit degradation temperature must be evaluated. Hence, the present work investigated the accelerated thermal aging of $40 \mathrm{vol} \%$ fique fabric-reinforced epoxy composite and the matrix itself, here named as plain epoxy (PE).

\section{Materials and Methods}

\subsection{Materials}

The fique fabric, Figure 1, was purchased in the market of Medellin, Colombia, by one of the authors of this work (H.A.C.L.). The fabric areal density, $859 \mathrm{~g} / \mathrm{cm}^{2}$, and volume 
density, $1.53 \mathrm{~g} / \mathrm{cm}^{3}$, were measured according to the corresponding standards in a previous article [40]. The matrix was the diglycidyl ether of bisphenol A (DGEBA) epoxy resin mixed with the triethylenetetramine (TETA) hardener in the stoichiometric proportion phr 13. Both DGEBA and TETA were supplied by Epoxyfiber, Rio de Janeiro, Brazil.

\subsection{Composite Fabrication}

The $40 \mathrm{vol} \%$ fique fabric-epoxy matrix composite was fabricated by placing the previously dried fabric piece as ply layers inside a steel mold, and DGEBA-TETA resin was also poured in. Laminated plates of $150 \times 120 \times 3.2 \mathrm{~mm}$ were made by the compression molding process and cured for $24 \mathrm{~h}$ at room temperature, inside the mold, under a 5-ton load. For DMA tests, these plates were cut into specimens, with dimensions of $50 \times 13 \times 3.2 \mathrm{~mm}^{3}$, in a Buehler Isomet cutoff machine (Lake Bluff, Lake County, IL, USA) using a diamond blade. Methods of accelerated thermal aging, as further described, were applied to these specimens.

\subsection{Accelerated Aging}

The fique fabric-epoxy composite and plain epoxy samples were subjected to an accelerated aging test performed in air chambers (Nova Instruments, Wakefield, MA, USA) at $170{ }^{\circ} \mathrm{C}$ for progressively increasing time lengths $(0,3,5$, and 10 days). The aging temperature of $170{ }^{\circ} \mathrm{C}$ was selected as the limit temperature before degradation in both the epoxy $[41,42]$ and the fique fabric, as further discussed in the corresponding thermogravimetric curves. Precaution was taken that the samples would not touch each other or the inner walls. Table 1 lists the nomenclatures used for the samples in this work.

Table 1. Nomenclature adopted for DMA specimens.

\begin{tabular}{ccccc}
\hline \multirow{2}{*}{ Material } & \multicolumn{4}{c}{ Aging Times (Hours at 170 $\left.{ }^{\circ} \mathbf{C}\right)$} \\
\cline { 2 - 5 } & $\mathbf{0}$ & $\mathbf{7 2}$ & $\mathbf{1 2 0}$ & $\mathbf{2 4 0}$ \\
\hline Plain epoxy & PE-T0 & PE-T72 & PE-T120 & PE-T240 \\
Composite & FC-T0 & FC-T72 & FC-T120 & FC-T240 \\
\hline
\end{tabular}

- $\quad 0 \mathrm{~h}$ (no aging): control sample;

- $\quad$ Aging temperature: $170^{\circ} \mathrm{C}(\mathrm{T})$; and

- $\quad$ Aging time: $72,120,240 \mathrm{~h}$.

The mass and dimensions, particularly the thickness, of the fique fabric-epoxy composite samples were measured before and after aging using a 0.001-g precision Gehaka scale and a 0.01-mm Mitutoyo digital caliper, respectively.

\subsection{Experimental Procedures}

\subsubsection{Scanning Electron Microscopy (SEM) Analysis}

The microstructural properties, damage mechanisms, and degradation were monitored using scanning electron microscopy (SEM) images of the plain epoxy and fique fabric composite, in aged and unaged states. A model Quanta FEG250 FEI microscope Thermofisher Scientific, Hillsboro, OR, USA, operating with secondary electrons at $28 \mathrm{kV}$ was used. Samples were gold-sputtered for electron conduction. The study focused on the accelerated aging of the surface layer of the composite and the plain epoxy, which means no "in core" analysis was intended.

\subsubsection{Thermogravimetric Analysis (TGA)}

TGA curves of epoxy and fique fabric composites were carried out in a Shimadzu equipment, Tokyo, Japan. Samples were crushed and put in a platinum crucible to be analyzed under nitrogen atmosphere in a temperature range from $20^{\circ} \mathrm{C}$ to $700{ }^{\circ} \mathrm{C}$ at a heating rate of $10^{\circ} \mathrm{C} / \mathrm{min}$. 


\subsubsection{Dynamic Mechanical Analysis (DMA)}

DMA was used to characterize the temperature-dependent viscoelastic properties of the materials described in Table 1 . The tests were performed using a dynamic mechanical analyzer DMA Q800 from TA Instruments (New Castle, DE, USA) operating at a frequency of $1 \mathrm{~Hz}$ with a heating rate of $3{ }^{\circ} \mathrm{C} / \mathrm{min}$ under a nitrogen atmosphere. A three-point bending mode was used for all the samples. Curves of storage modulus $\left(\mathrm{E}^{\prime}\right)$, loss modulus $\left(\mathrm{E}^{\prime \prime}\right)$, and $\tan$ delta $(\tan \delta)$ in the temperature range from $30^{\circ} \mathrm{C}$ to $190^{\circ} \mathrm{C}$ were recorded just for the first run.

\section{Results and Discussions}

In the present investigation, the effects of thermal aging on the morphology and thermoviscoelastic-mechanical properties were evaluated at $170{ }^{\circ} \mathrm{C}$ for different exposure times.

\subsection{Mass and Thickness Variations}

Figure 2 shows the mass and thickness variations in the plain epoxy and fique fabric composite caused by accelerated aging. In this figure, one can notice a mass increase of $6 \%$ and $1 \%$ for the composite (FC-T72) and plain epoxy (PE-T72) at $72 \mathrm{~h}$ of exposure time, respectively. Hinkley et al. [43] reported that it is common to verify this slight initial weight gain given by the formation of oxidation products. By contrast, a higher mass loss of $14 \%$ (FC-T120) and 13\% (PE-T120) were observed in the samples exposed for $120 \mathrm{~h}$. Additionally, after aging for $240 \mathrm{~h}$, the FC-T240 and PE-T240 also presented a mass loss of $12 \%$ and $8 \%$, respectively. This accelerated weight loss $(>10 \%)$ might indicate the material embrittlement and occurrence of cracks, which increase the surface area of contact with oxygen $[43,44]$. Based on this result, regarding the mass loss, the fique fabric composite exposed for $120 \mathrm{~h}$ (FC-T120) was the most unstable condition. Furthermore, a high shrinkage of $15 \%$ was also displayed by the FC-T120 composite, which might be associated with the outgassing of resin oxidation by-products [45].

\subsection{Effects of Thermal Aging on Fique Fabric}

Figure 3 shows the SEM images of fique fiber unaged and aged with different exposure times. Microcracks can be noted along the fiber length exposed for $72 \mathrm{~h}$ (Figure 3b). The effect of thermal degradation was more evident after aging for $120 \mathrm{~h}$ (Figure 3c), for which we observed microfibrils exposed in the fique fiber surface. In Figure $3 \mathrm{~d}$, it is also noted the microfibrils' breakage after $240 \mathrm{~h}$ of exposure. Collapsed microfibrils in heat-treated kenaf fibers were observed by Azwa and Yousif [46] and also reported by Ezekiel et al. [47] for coir fibers. The authors suggested that the presence of these collapsed microfibrils might be associated with the depolymerization of hemicellulose from $180{ }^{\circ} \mathrm{C}$ and can also contribute to the weight loss of the composites. Hence, the thermal stability was enhanced with an increase in hemicellulose content, as well as with a higher crystalline cellulose amount. Conversely, an increase in extractive content led to a reduction in thermal stability [29]. In other words, the initial thermal degradation started with hemicellulose degradation, as shown in Figure 4, which presented the scheme of the relationship between NLF components and thermal aging. Therefore, based on Figure 3, hemicellulose loss and oxidation might be the major mechanisms for the microstructure changes on the fique fiber exposed to thermal aging.

\subsection{Effects of Thermal Aging on Plain Epoxy}

It is well known that epoxy properties are strongly dependent on the usage conditions, such as time and temperature. When exposed to temperatures of about $100-200{ }^{\circ} \mathrm{C}$, polymers suffer from softening, creep, distortion, and deterioration of mechanical properties [48]. Figure 5 shows the occurrence of voids formed since the first exposure time, as well as the change of color, which is related to the irreversible aging mechanism. The oxidative evolution of carbonyl groups in the epoxy resin was the reason for the surface brownish color. In addition, microcracks could be observed in some aged samples. 

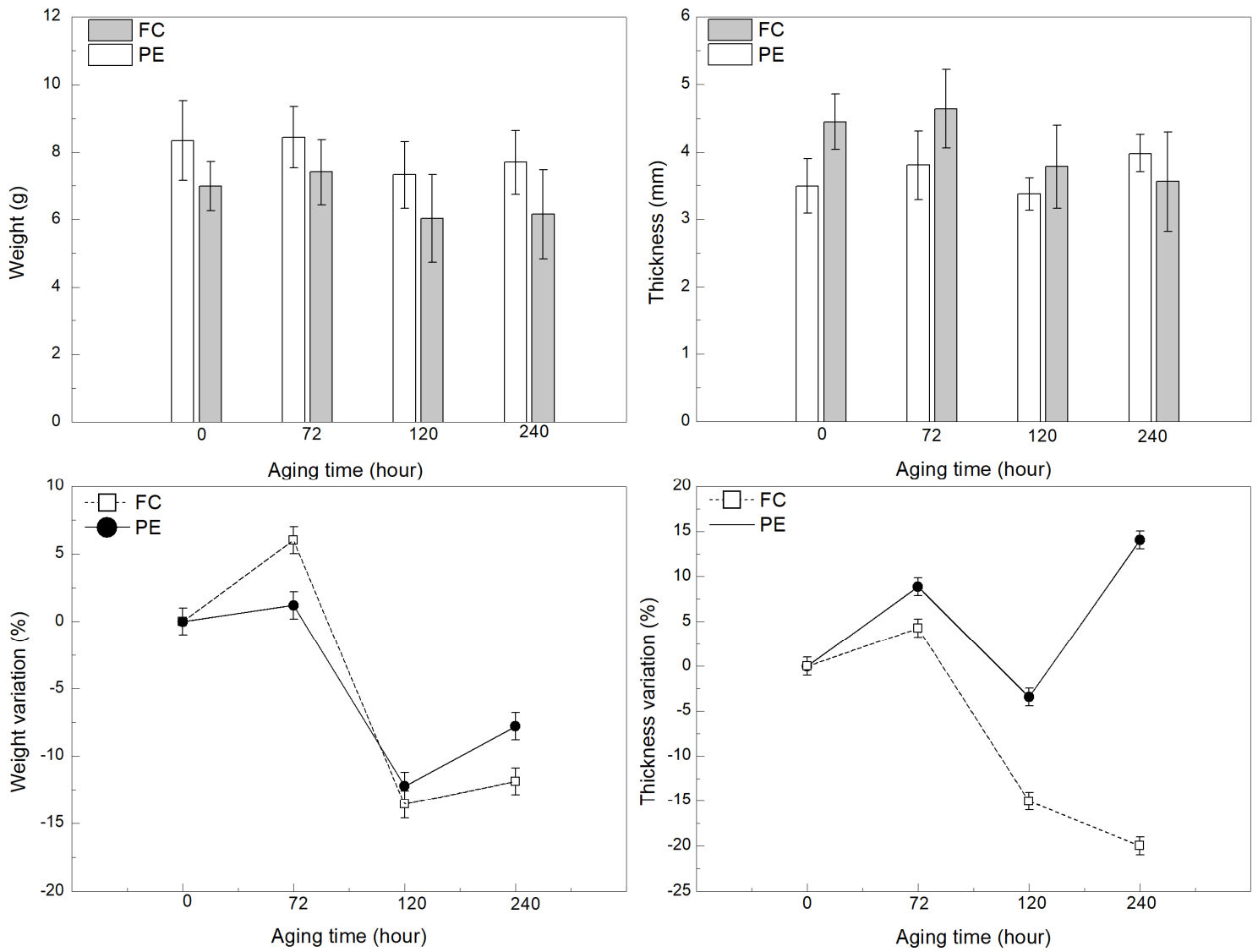

Figure 2. Mass and thickness losses of the plain epoxy (PE) and fique fabric reinforcing epoxy composite (FC) during thermal aging.

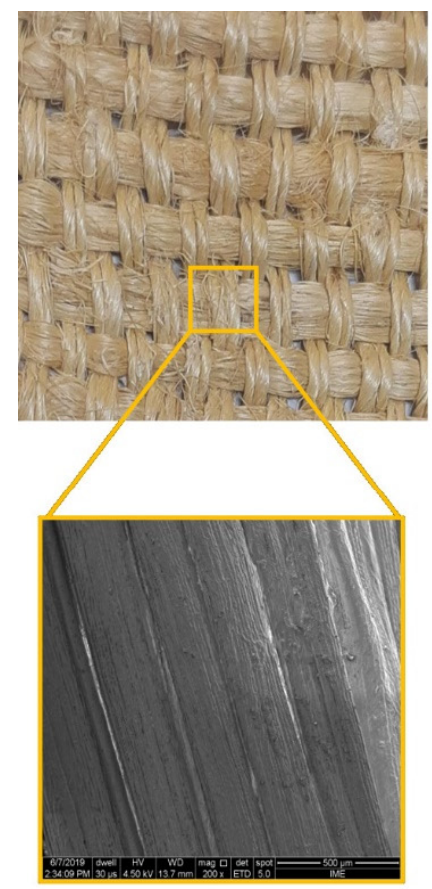

(a)

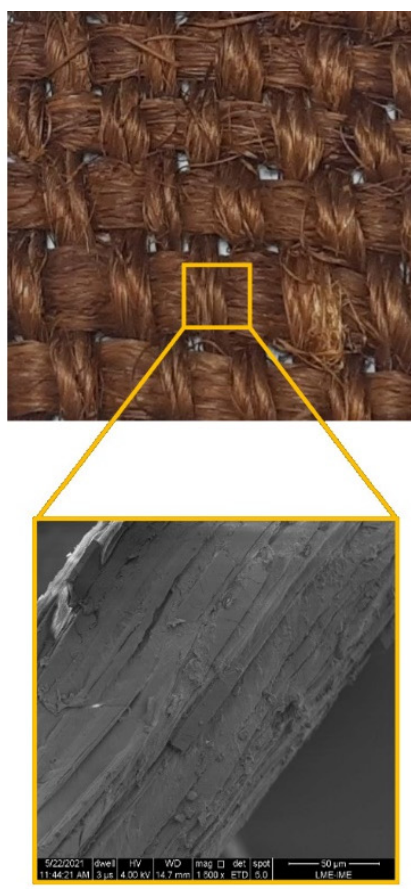

(b)

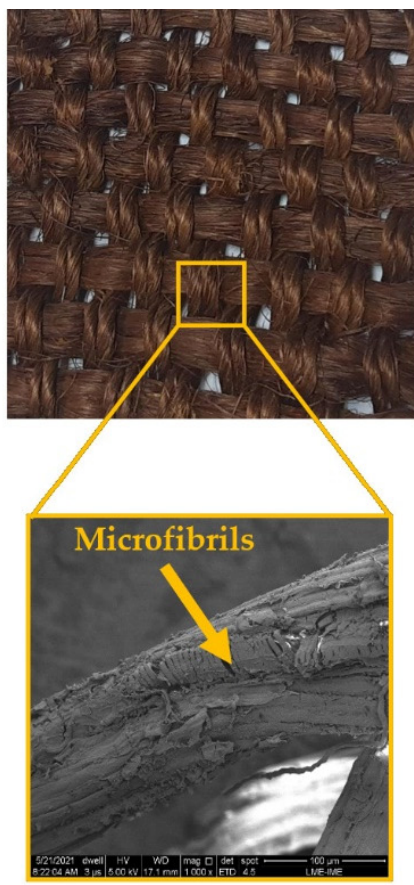

(c)

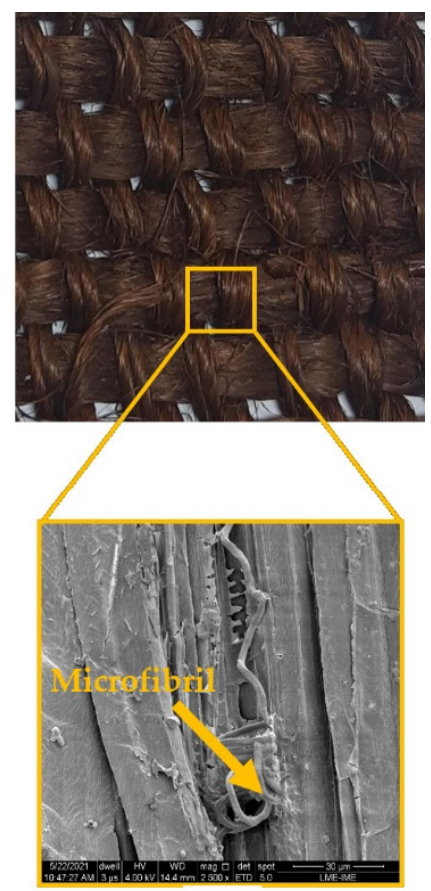

(d)

Figure 3. Visual changes and SEM micrographs of fique fiber after high temperature aging: (a) 0 h; (b) 72 h; (c) 120 h; (d) $240 \mathrm{~h}$ at high temperature $\left(170^{\circ} \mathrm{C}\right)$. 


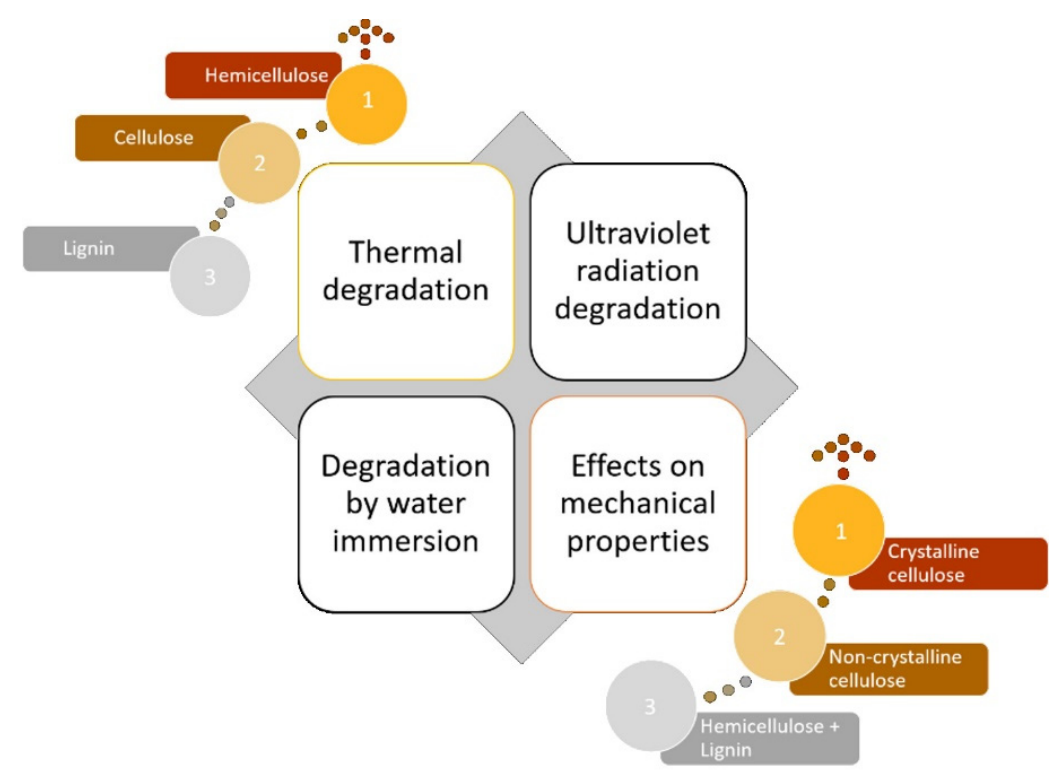

Figure 4. Main components of natural fibers and their orderly influence for thermal degradation and mechanical properties.

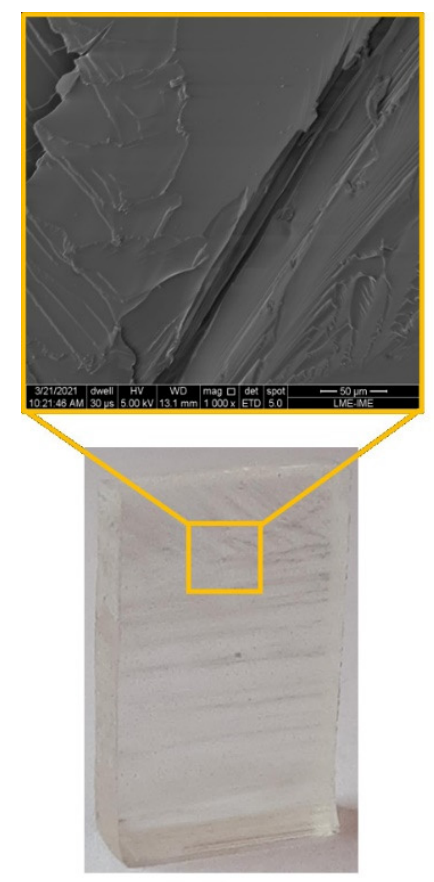

(a)

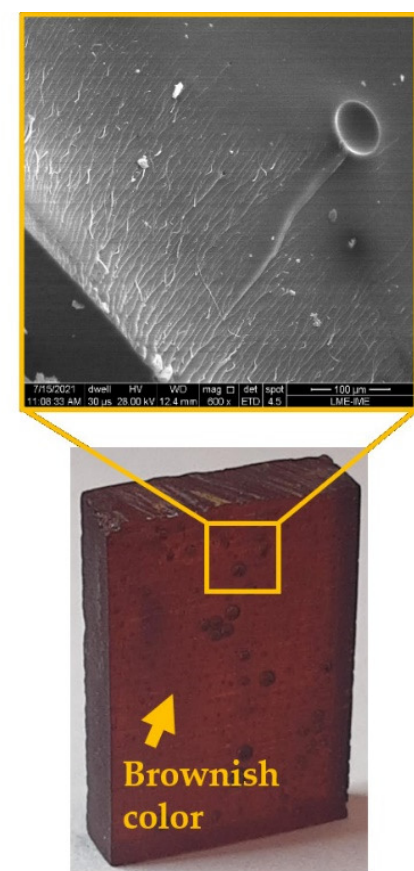

(b)

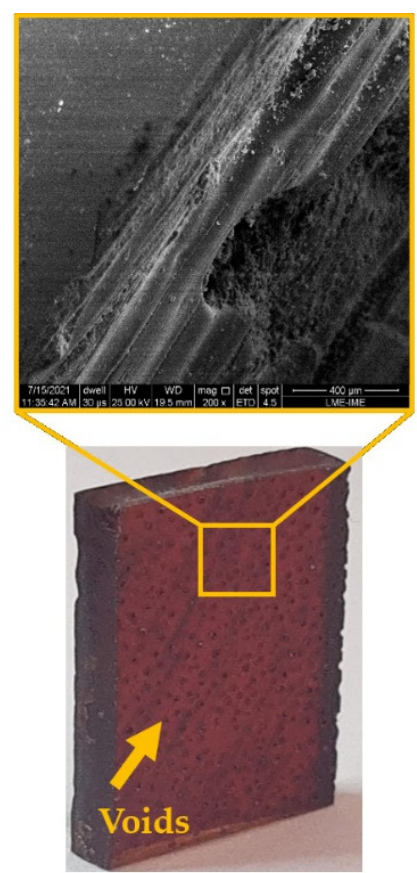

(c)

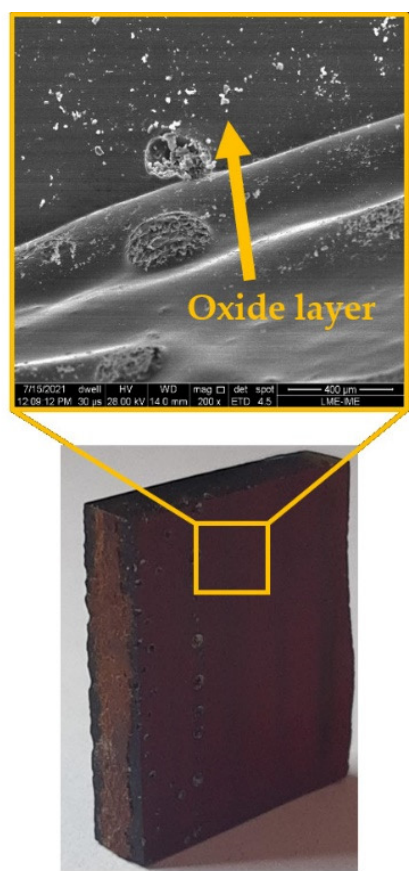

(d)

Figure 5. Visual changes and SEM micrographs of plain epoxy thermally aged in (a) $0 \mathrm{~h}$; (b) $72 \mathrm{~h}$; (c) $120 \mathrm{~h}$; and (d) $240 \mathrm{~h}$ exposure time.

The aging of polymers in an oxidative environment, such as the one employed in this study, leads to a heterogeneous degradation, which is governed by the diffusion of oxygen through the polymer [41]. Previous studies [41,48,49] have indicated that thermal aging has a strong influence on the properties of polymer-based materials. The white-colored spots in the SEM image of Figure $5 \mathrm{~d}$ are related to an oxide layer observed in all thermally aged epoxies [50]. In addition, one should note that the voids act as reservoirs of them [51]. 


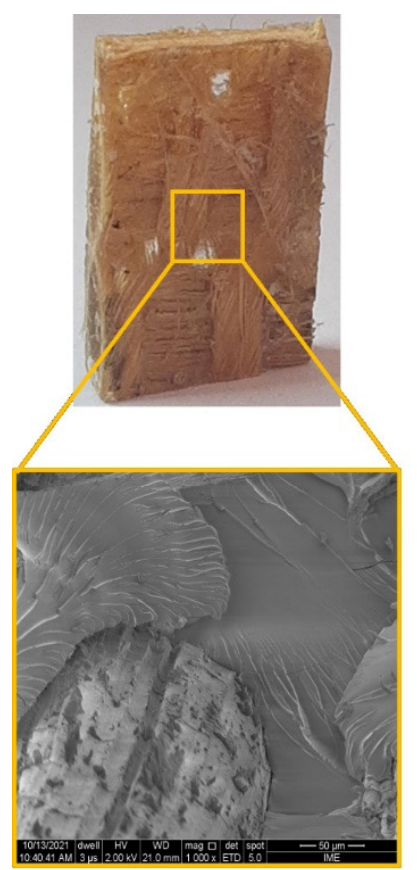

(a)

\subsection{Effects of Thermal Aging on Fique Fabric-Reinforced Epoxy Composite}

SEM images of fique fabric-reinforced epoxy composite unaged and thermally aged are shown in Figure 6. In this figure, it can be observed that the exposure to thermal aging increased the damage on fique fabric-reinforced epoxy composites through fiber pullout, fiber breakage, tearing, debris, and matrix cracking [52].

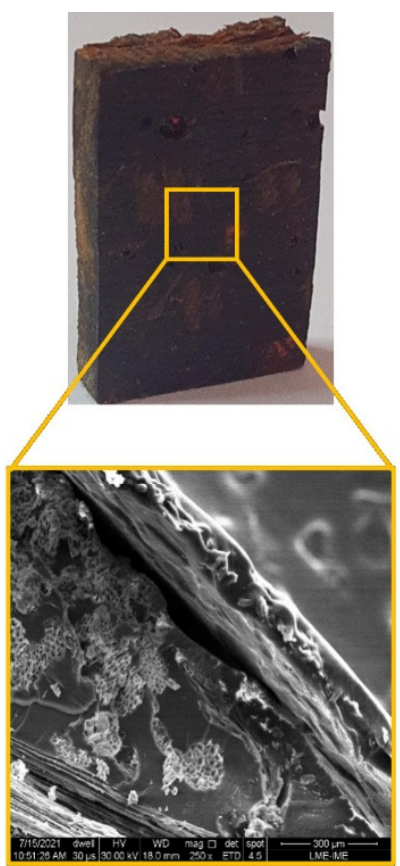

(b)

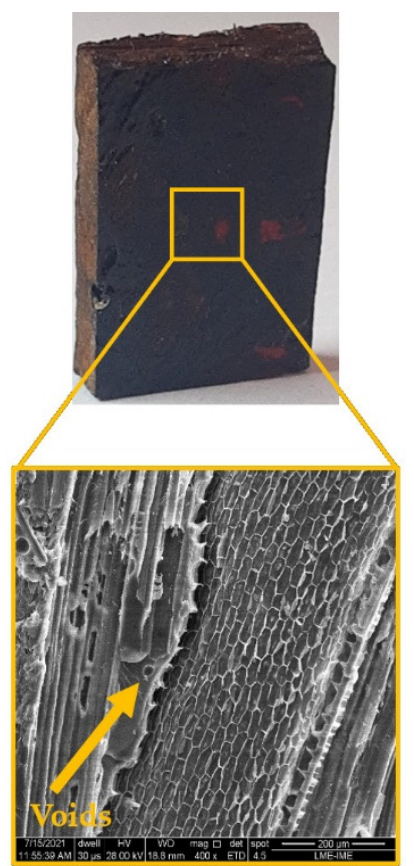

(c)

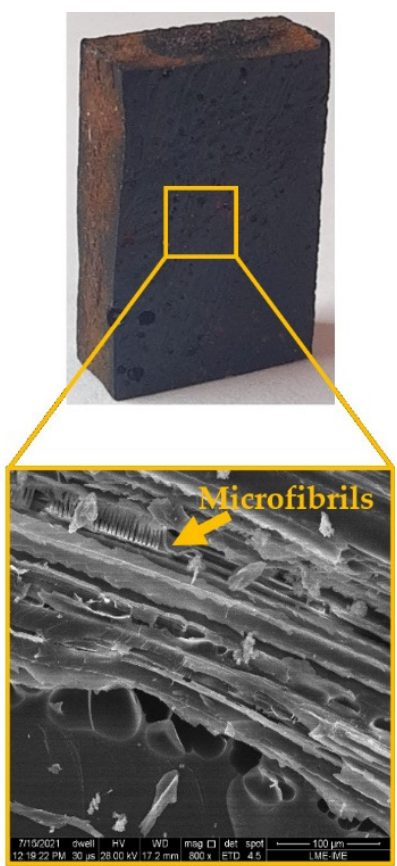

(d)

Figure 6. Visual changes and corresponding high magnification SEM micrographs of fique fabric-reinforced epoxy composites thermally aged in (a) 0 h; (b) 72 h; (c) 120 h; and (d) $240 \mathrm{~h}$ exposure time.

Thermal oxidation of the fique fabric-epoxy composite introduced damage at the fiber-matrix interfaces, which caused the formation of microcracks and degraded the structural property. It was possible to note that all exposure times promoted the fibermatrix debonding and fiber fibrillation due to the degradation of less stable components of the fique fibers as well as shrinkage of the epoxy. The induced thermal stress may be relieved by crack formation in the matrix and fiber failure (Figure 3). Both matrix cracking and fiber failure degrade the mechanical properties of the composite.

All samples of the fique fabric, plain epoxy, and fique fabric composites revealed modification in the macrostructural level by the color change. A brownish layer formation at the sample surface was also reported in the literature $[46,49,53,54]$.

\subsection{TGA of Unaged Epoxy and Composite}

Figure 7 shows thermogravimetric curves for plain epoxy and unaged fique fabric composites. These curves revealed that $170{ }^{\circ} \mathrm{C}$ might be considered the maximum temperature before a sudden decrease in mass loss associated with effective thermal degradation of the material. These TGA results justify the choice of $170{ }^{\circ} \mathrm{C}$ for the basic temperature for different aging times selected in the present work.

\subsection{Effects of Thermal Aging on DMA}

The dynamic mechanical relaxation behavior of fique fabric-reinforced epoxy composites and plain epoxy annealed at $170{ }^{\circ} \mathrm{C}$ up to $240 \mathrm{~h}$ and unaged was investigated. The main DMA parameters for both aged and unaged $40 \mathrm{vol} \%$ fique fabric composite and plain epoxy are shown in Tables 2 and 3, respectively. Each of these parameters is further discussed in the subsections below. 


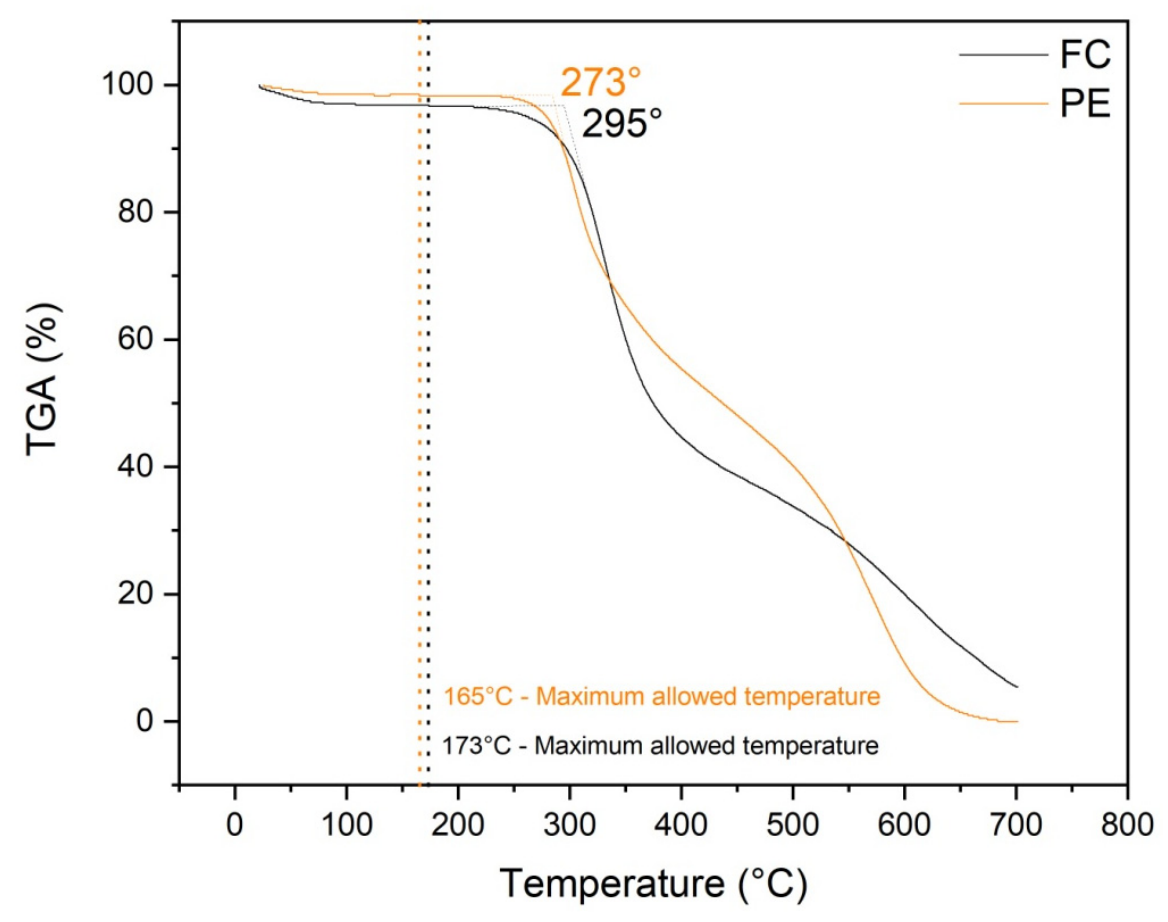

Figure 7. TGA curves of plain epoxy and unaged fique fabric composites.

Table 2. DMA parameters obtained for the composite reinforced with $40 \mathrm{vol} \%$ fique fabric, aged at high temperature and unaged.

\begin{tabular}{ccccccc}
\hline Material & \multicolumn{2}{c}{$\mathbf{E}^{\prime}{ }_{\text {30 }}$} & \multicolumn{2}{c}{$\mathrm{E}^{\prime \prime}$} & \multicolumn{2}{c}{ Tan $\delta$} \\
\hline & $\begin{array}{c}\text { Storage } \\
\text { Modulus } \\
\text { at 30 }{ }^{\circ} \mathbf{C} \\
\mathbf{( G P a )}\end{array}$ & $\begin{array}{c}\text { Lower } \\
\text { Limit of } \\
\mathbf{T g}\left({ }^{\circ} \mathbf{C}\right)\end{array}$ & $\begin{array}{c}\text { Loss } \\
\text { Modulus } \\
\text { Peak } \\
\mathbf{( G P a )}\end{array}$ & $\begin{array}{c}\text { Peak Tem- } \\
\text { perature } \\
\left({ }^{\circ} \mathbf{C}\right)\end{array}$ & $\begin{array}{c}\text { Tan } \delta \text { Peak } \\
(\mathbf{G P a})\end{array}$ & $\begin{array}{c}\text { Peak Tem- } \\
\text { perature } \\
\left({ }^{\circ} \mathbf{C}\right)\end{array}$ \\
\hline FC-T0 & 2.81 & 61.77 & 0.29 & 72.95 & 0.40 & 86.82 \\
FC-T72 & 2.94 & 92.40 & 0.22 & 107.55 & 0.40 & 116.71 \\
FC-T120 & 2.64 & 96.03 & 0.17 & 105.14 & 0.18 & 150.19 \\
FC-T240 & 2.12 & 81.05 & 0.15 & 101.39 & 0.58 & 179.71 \\
\hline
\end{tabular}

Table 3. DMA parameters obtained for plain epoxy, aged at high temperature and unaged.

\begin{tabular}{ccccccc}
\hline Material & \multicolumn{2}{c}{$\mathbf{E}_{\text {glassy }\left(\mathbf{3 0}^{\circ} \mathbf{C}\right)}$} & \multicolumn{2}{c}{$\mathbf{E}^{\prime \prime}$} & \multicolumn{2}{c}{ Tan $\delta$} \\
\hline & $\begin{array}{c}\text { Storage } \\
\text { Modulus } \\
\text { at } \mathbf{3 0}{ }^{\circ} \mathbf{C} \\
\mathbf{( G P a )}\end{array}$ & $\begin{array}{c}\text { Lower } \\
\text { Limit of } \\
\mathbf{T g}\left({ }^{\circ} \mathbf{C}\right)\end{array}$ & $\begin{array}{c}\text { Loss } \\
\text { Modulus } \\
\text { Peak } \\
\mathbf{( G P a )}\end{array}$ & $\begin{array}{c}\text { Peak Tem- } \\
\text { perature } \\
\left({ }^{\circ} \mathbf{C}\right)\end{array}$ & $\begin{array}{c}\text { Tan } \delta \text { Peak } \\
(\mathbf{G P a})\end{array}$ & $\begin{array}{c}\text { Peak Tem- } \\
\text { perature } \\
\left({ }^{\circ} \mathbf{C}\right)\end{array}$ \\
\hline PE-T0 & 3.21 & 97.97 & 0.25 & 93.61 & 0.51 & 117.81 \\
PE-T72 & 2.07 & 102.37 & 0.11 & 112.86 & 0.24 & 145.29 \\
PE-T120 & 2.65 & 99.82 & 0.28 & 142.88 & 0.31 & 151.29 \\
PE-T240 & 2.99 & 97.04 & 0.37 & 151.88 & 0.38 & 169.13 \\
\hline
\end{tabular}

\subsubsection{Storage Modulus}

Figure 8 presents the storage modulus ( $\left.\mathrm{E}^{\prime}\right)$ for both fique fabric composites (Figure $8 \mathrm{a}$ ) and plain epoxy (Figure 8c) samples aged at $170{ }^{\circ} \mathrm{C}$ in different exposure times and unaged ones. It was observed that exposure time had a strong influence on the relaxation behavior of these materials, which is associated with the glass transition temperature ( $\mathrm{Tg}$ ) from crystalline state to rubbery plateau [21]. For better identification of the glassy plateau in the plain epoxy (unaged and aged), see Figure 8a-d with storage modulus $\mathrm{Y}$ axis in $\log$ 
scale, respectively. Figure $8 \mathrm{~d}$ also shows dotted curves of the same DGEBA/TETA epoxy corresponding to the first and second DMA runs, as reported by Margem et al. [55].

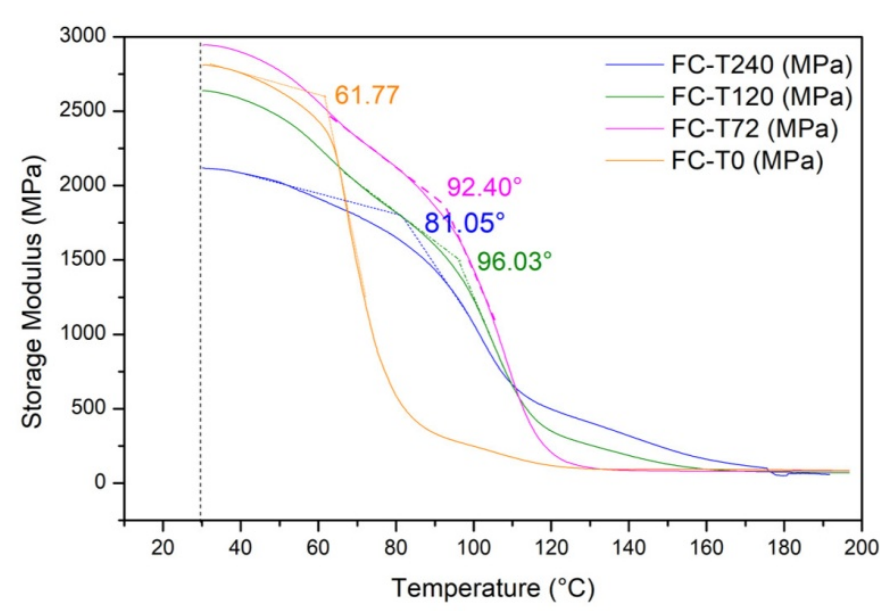

(a)

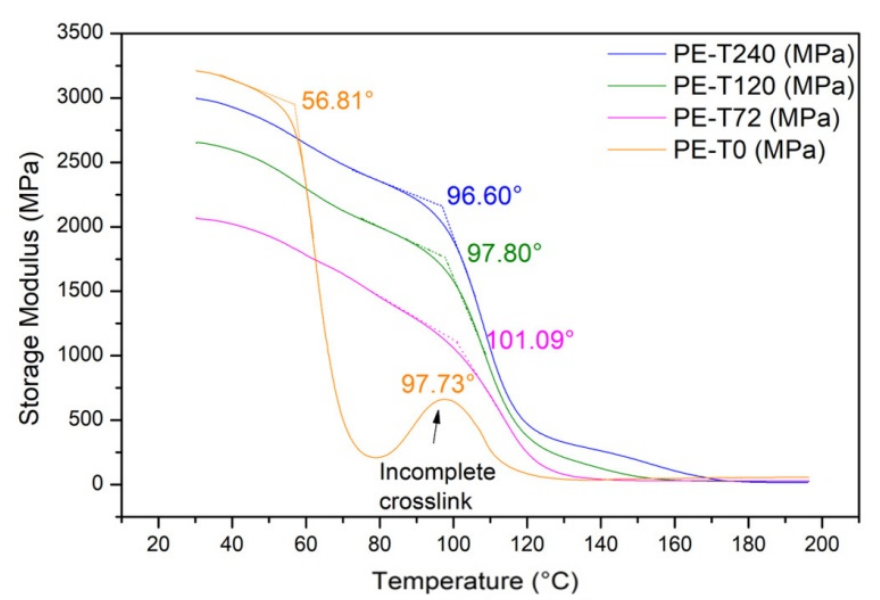

(c)

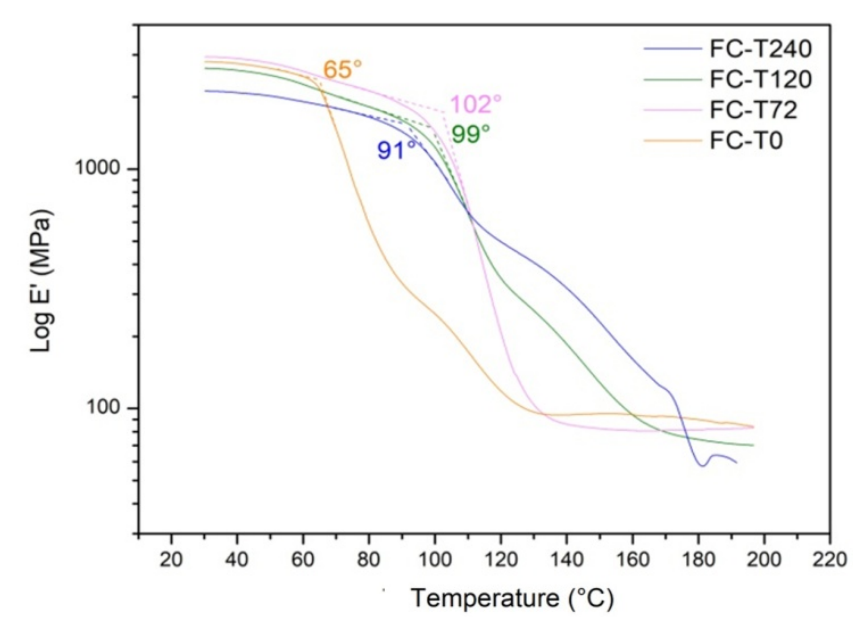

(b)

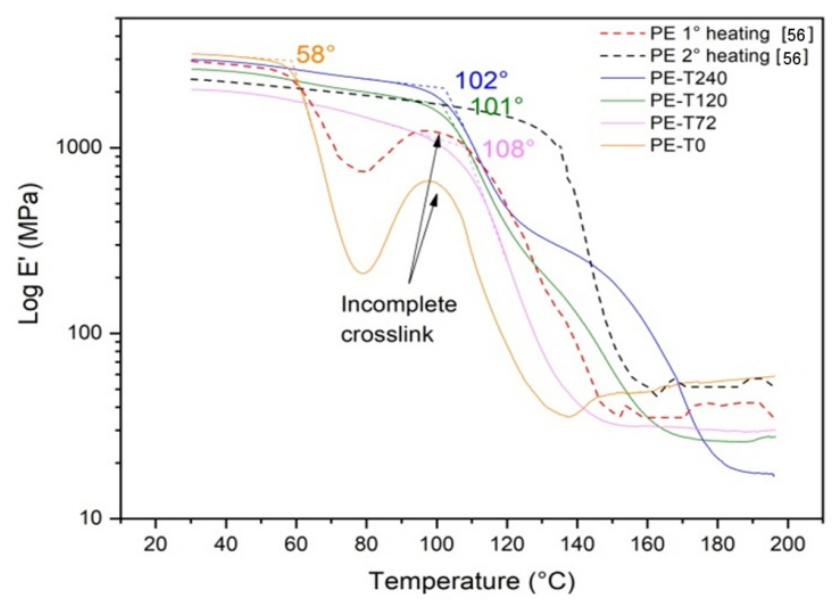

(d)

Figure 8. Storage modulus ( $\left.E^{\prime}\right)$ curves for samples unaged and thermally aged at different conditions: (a) fique fabric epoxy composites; (b) $\log E^{\prime}$ versus temperature for fique fabric epoxy composite; (c) plain epoxy; and (d) log E' versus temperature for plain epoxy with additional first and second runs, dotted curves of the same DGEBA/TETA epoxy adopted from [55].

One should notice that the E' value of the FC-T72 was the highest among the conditions due to an increase of the chain mobility during the glassy/rubbery transition [10]. By contrast, the storage modulus decreased for $240 \mathrm{~h}$ aging (FC-T240), which was associated with the decrease in the material viscoelastic stiffness [56], indicating the degradation at the fiber-matrix interface, as verified in the SEM analyses. Additionally, it is worth mentioning the presence of a broad peak around $98^{\circ} \mathrm{C}$ for the unaged plain epoxy. This can be attributed to the post-curing reaction given by the incomplete crosslinking. This peak in the value of $E^{\prime}$ occurred in the first run of the DMA test, which corresponded to the experimental procedure in the present work. Indeed, a previous work [56] using the same DGEBA/TETA epoxy matrix reinforced with ramie fibers reported a similar peak around $100{ }^{\circ} \mathrm{C}$ that disappeared in the second run. Such an $\mathrm{E}^{\prime}$ peak was attributed to an additional crosslink completion process. Stark [57] also reported an $\mathrm{E}^{\prime}$ peak behind $175^{\circ} \mathrm{C}$ in a type 6376 epoxy from Hexcel, for application in aircraft carbon-epoxy composites. Similarly, the author indicated that crosslinking would be the expected consequence of this peak.

Furthermore, the results indicated a more pronounced effect of exposure time on aged composite samples in comparison to plain epoxy ones. It might have been caused 
by the fiber-matrix interface weakening on the composites. Nevertheless, for both fique fabric composites and plain epoxy, an increase of $\mathrm{Tg}$ was observed for the samples aged up to $120 \mathrm{~h}$. The results revealed an increase of up to $45^{\circ} \mathrm{C}$ on $\mathrm{Tg}$, the same as found by Inamdar et al. [41].

Another point worth noting in Figure $8 \mathrm{~d}$ is the onset of the sudden drop in the value of $E^{\prime}$ after a glassy plateau, which extended well under room temperature in the work of Stark [57]. The author mentioned that crosslinking-induced vitrification should lead to a plateau in E'. Aging at $170^{\circ} \mathrm{C}$ significantly extended the onset of the sudden drop to temperatures above $100^{\circ} \mathrm{C}$, which might also be attributed to crosslinking triggered by heating above $\mathrm{T}_{\mathrm{g}}$. This provided the thermal energy to activate monomers to further crosslink and then the storage modulus achieved a plateau associated with final crosslinking reactions [58].

\subsubsection{Loss Modulus}

It is well known that another noticeable effect of the 3D molecular arrangement of the polymer matrix is the main peak in the curve of loss modulus (E"). Figure 9 shows the loss modulus (E") vs. temperature for the fique fabric composite and plain epoxy at different times of aging. The maximum value of $E^{\prime \prime}$ was attributed to the relaxation alpha $(\alpha)$ peak [20], which was associated with the mobility of the polymer chains in the transition from crystalline to an amorphous molecular structure. In this figure, one should notice that the $\alpha$-peaks are displaced to higher temperatures in comparison to plain epoxy. This indicates a decrease in the flexibility of the epoxy chains caused by the incorporation of fique fabric. Additionally, the broadening of this peak for higher exposure times denotes the evolution of the macromolecular network at the fiber-matrix interface and debonding during aging, modifying the relaxation processes associated with the $\alpha$-transition [59].

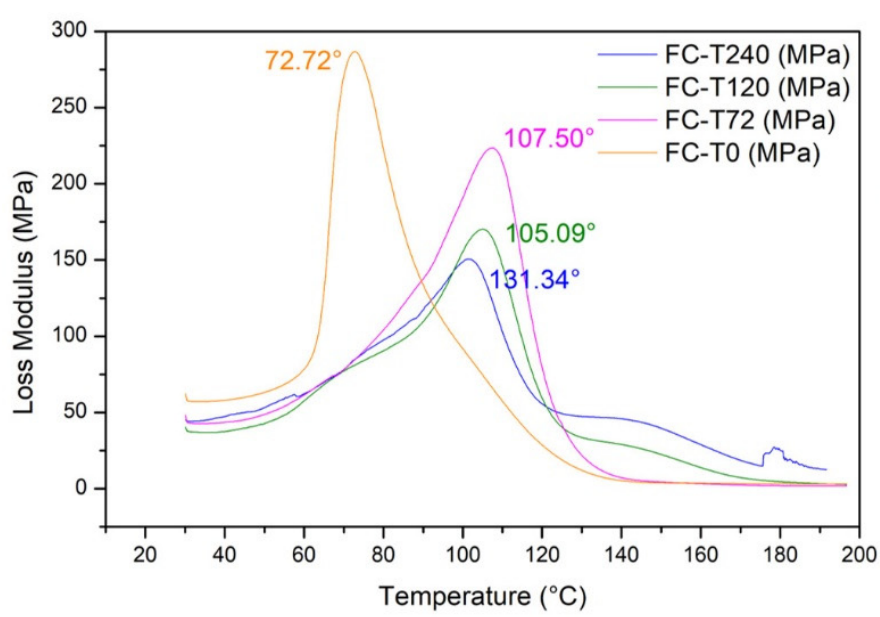

(a)

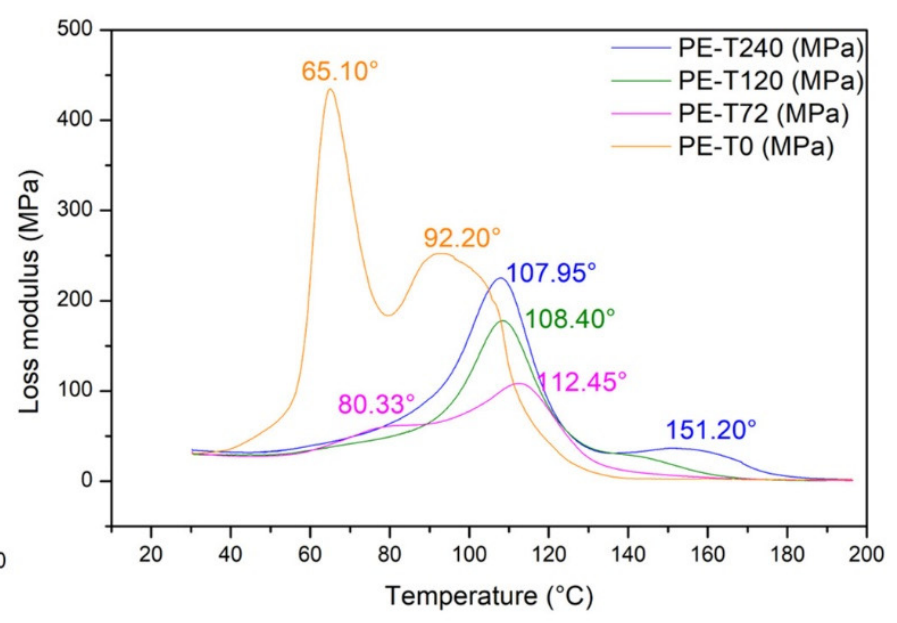

(b)

Figure 9. Loss modulus (E") vs. temperature with glass transition temperatures (Tg) highlighted for samples unaged and thermally aged at different conditions: (a) fique fabric-reinforced epoxy composites; (b) plain epoxy.

\subsubsection{Tan Delta}

The loss factor $(\tan \delta)$ is the $E^{\prime \prime} / E^{\prime}$ ratio, which represents the mechanical damping or molecular internal friction of a viscoelastic configuration. The effect of time aging on the $\tan \delta$ for the fique fabric-reinforced epoxy composite and plain epoxy is shown in Figure 10. The $\tan \delta$ curves show an expected peak shift to lower temperatures after aging. An apparent increase in peak intensity is observed for FC-T72, indicating higher mobility of the macromolecular chains [60], which corroborates the analysis performed for $\mathrm{E}^{\prime}$ in Figure 8. For samples aged at higher times, the trend of broadening and the decrease of $\tan \delta$ peaks suggests the weakness of the material [10]. Furthermore, the heterogeneity of 
the macromolecular networks with the formation of new crosslinked domains is confirmed by extra peaks in FC-T240 (Figure 10a).

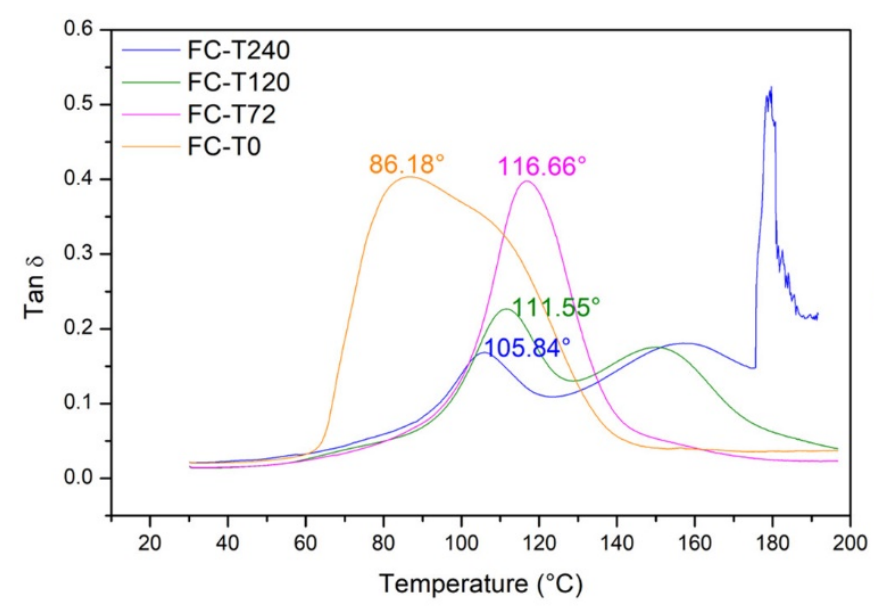

(a)

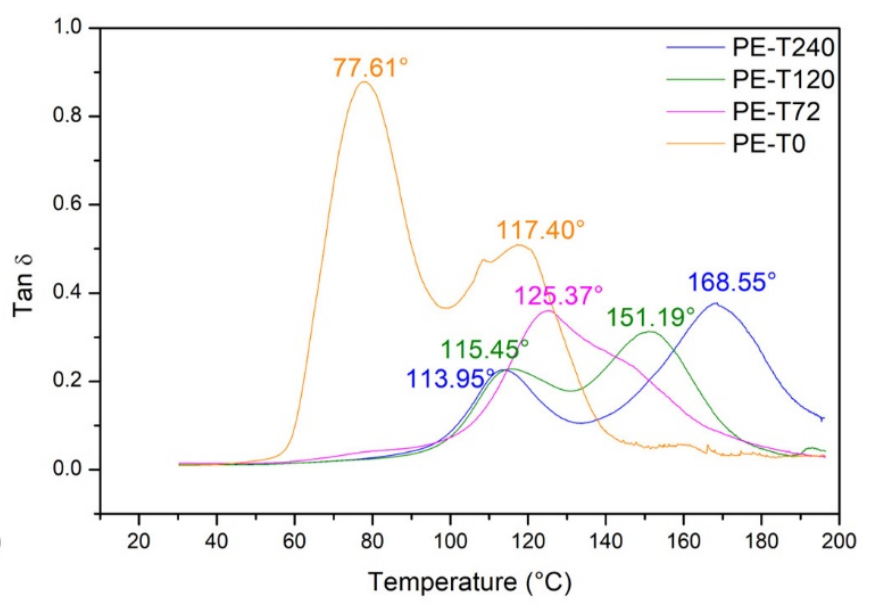

(b)

Figure 10. Effect of time aging on the loss tangent ( $\tan \delta$ ) curves for: (a) fique fabric-reinforced epoxy composites; and (b) plain epoxy.

3.6.4. Modeling of the Loss Factor Curve: Evaluation with Exponentially Modified Gauss (EMG) Distribution Functions

DMA investigations revealed distinct changes in the shape of the loss factor $(\tan \delta)$ curve. One can note that the tan $\delta$ curves, in Figure 10, contain two apparent peak regions, i.e., exhibit at least two mobility fractions. The molecular interpretation of the involved aging phenomena on the tan $\delta$ curves was investigated by modeling with three exponentially modified Gauss (EMG) distribution functions. This model consisted of a convolution between Gauss distribution and exponential decay function, which was described in detail elsewhere [8]. The application of EMGs provided parameters of the sub-transition regions of the loss factor curve: (1) the peak areas $\left(\mathrm{A}_{i}\right) ;(2)$ the half peak width at half height of the Gaussian part of corresponding EMG $\left(\mathrm{w}_{\mathrm{i}}\right) ;(3)$ the temperature at peak maximum of Gaussian part of the EMG ( $\left.\mathrm{Tc}_{1}\right)$; and (4) the relaxation parameter in the exponential part of the EMG $\left(\mathrm{To}_{\mathrm{i}}\right)$ [7-9]. Figure 11 shows the loss factor description for fique fabric composite and plain epoxy with three EMGs. In this figure, the deconvoluted peaks for the different regions of molecular rearrangement processes correspond to the polymer fractions with different mobility [7-9]. After the baseline correction, a suitable function was selected to evaluate the area under the peaks. It can be noted that all graphs obtained a high $\mathrm{R}^{2}$ coefficient. The number of fit parameters obtained was equal to $N \times 4$, where $\mathrm{N}$ is the number of EMGs' fit functions and 4 means the number of parameters per EMG $\left(\mathrm{A}_{\mathrm{i}}, \mathrm{w}_{\mathrm{i}}, \mathrm{Tc}_{\mathrm{i}}, \mathrm{To}_{\mathrm{i}}\right)$.

Table 4 shows the parameters obtained from the EMG curves (Figure 11). This table reveals that almost all parameters were aging dependent, mainly in the second transition (peak 2), where its asymmetry decreased and its intensity increased. It was also noted that for all transitions of plain epoxy, the maximum temperatures of the Gauss parts of the EMGs $\left(\mathrm{Tc}_{1}, \mathrm{Tc}_{2}\right.$, and $\left.\mathrm{Tc}_{3}\right)$ increased with aging time. The same process was considered for fique fabric composite, and the EMGs' fit parameters are presented in Table 5.

The sum of peak areas is considered the total area of the loss factor curve, and for almost all conditions for both plain epoxy and fique fabric composites these values decreased. This means that restrictions on chains' mobility increased. Furthermore, a small peak area $\left(\mathrm{A}_{\mathrm{i}}\right)$ was caused by $(1)$ hindrance in mobility, $(2)$ increase of stiffness, and (3) increase of crosslinking. In addition, the peak temperature $\left(\mathrm{Tc}_{\mathrm{i}}\right)$ of the Gauss part can be interpreted as $\mathrm{Tg}$ of the relaxation free transition, i.e., transition without the exponential part; one has a pure Gauss distribution. By contrast, when the exponential relaxation $\left(\mathrm{To}_{\mathrm{i}}\right)$ was more pronounced, the higher was the residual internal friction. 
(a)

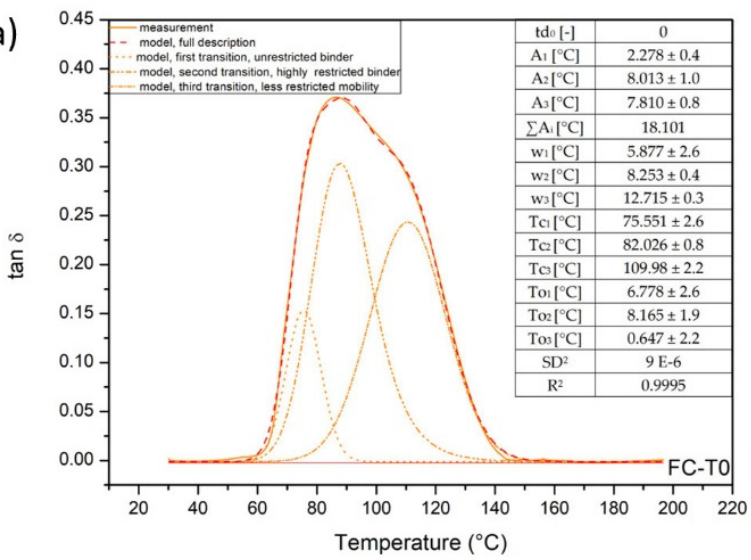

(b)

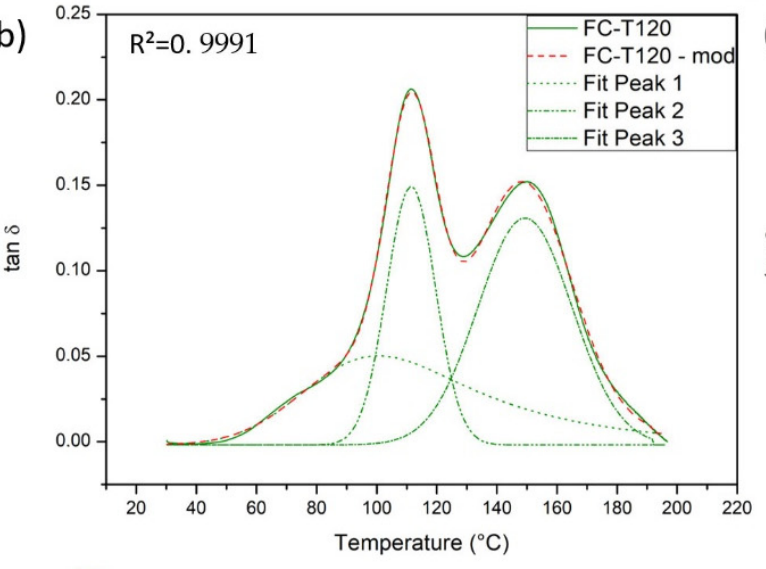

(d)

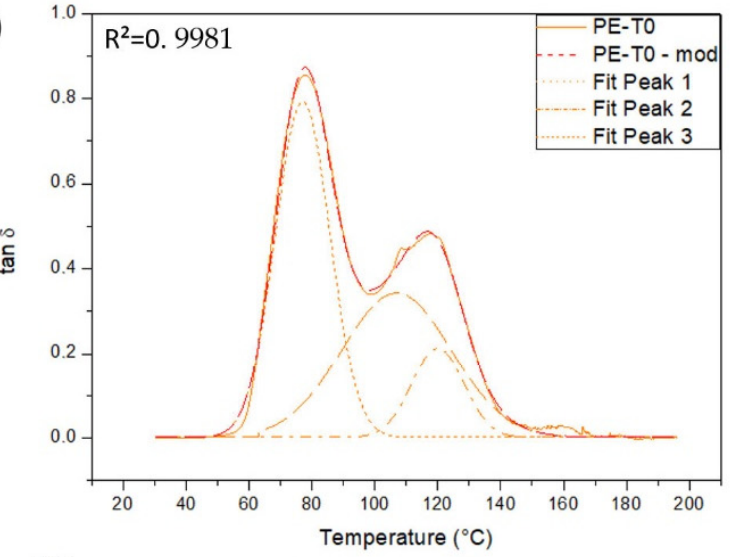

(f)

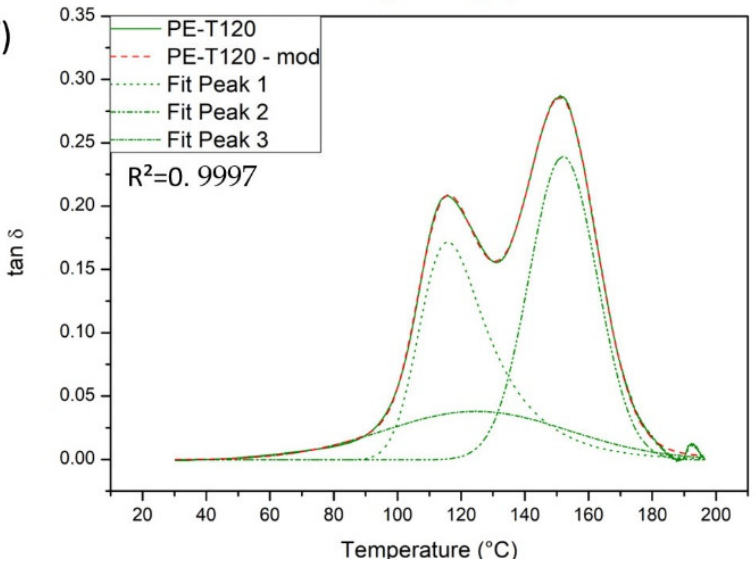

(c)

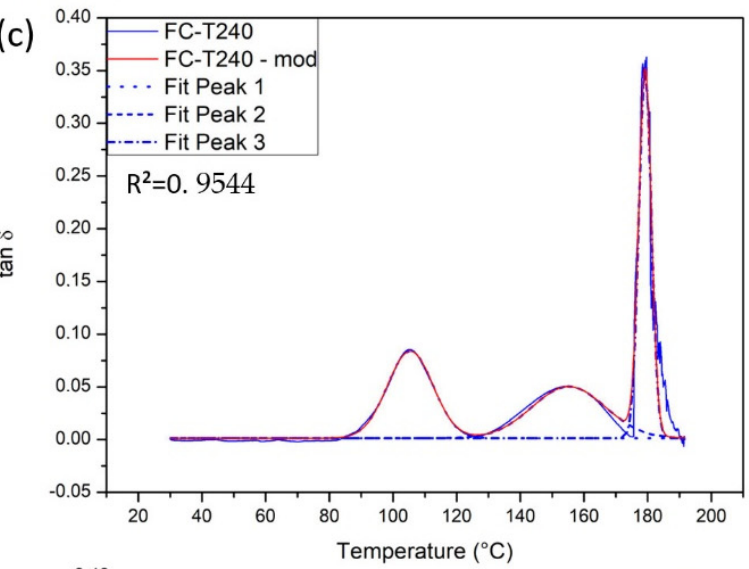

(e)

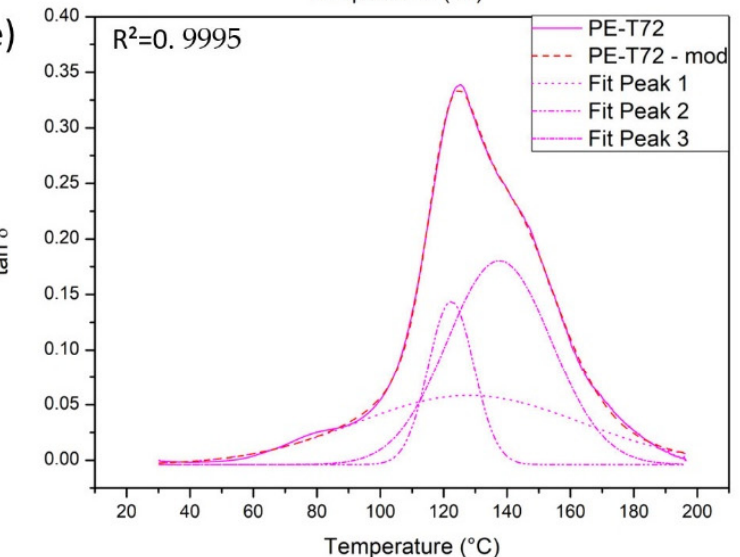

(g)

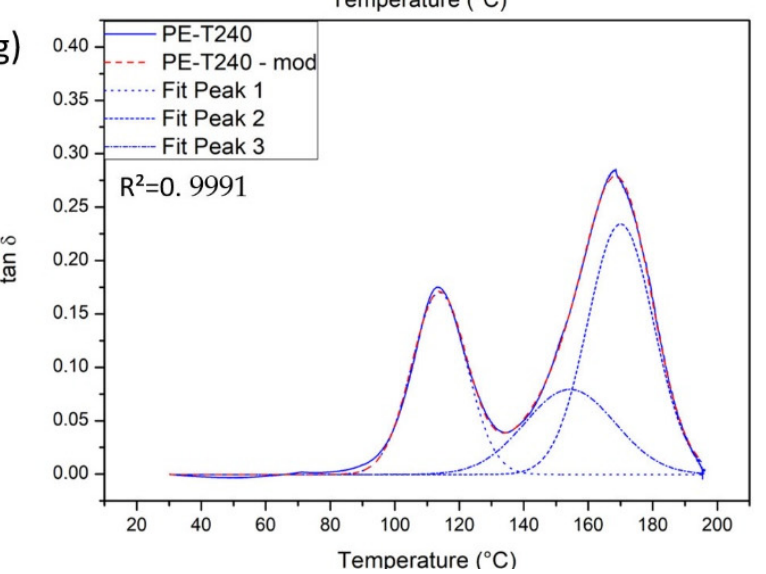

Figure 11. Description of loss factors of the plain epoxy and fique fabric composites in different aging conditions with three EMG functions. (The solid curves represent the original data and the dashed lines are relative to the result after multi-peak resolution.) (a) FC-T0; (b) FC-T120; (c) FC-T240; (d) PE-T0; (e) PE-T72; (f) PE-T120; and (g) PE-T240. 
Table 4. EMG fit parameters of the loss factor curves for plain epoxy as a function of aging at high temperature. The column named 'change' gives the ratio of values between the aged state at $170{ }^{\circ} \mathrm{C}, 240 \mathrm{~h}$, and the unaged state.

\begin{tabular}{ccccccc}
\hline \multicolumn{7}{c}{ Plain Epoxy } \\
\hline Aging Time & $\mathbf{0}$ & $\mathbf{7 2}$ & $\mathbf{1 2 0}$ & $\mathbf{2 4 0}$ & Change & Trend with Aging \\
\hline $\mathrm{A}_{1}$ & $17.239 \pm 0.1$ & $5.538 \pm 0.2$ & $5.157 \pm 0.1$ & $3.647 \pm 0.0$ & 0.21 & decrease \\
$\mathrm{A}_{2}$ & $4.379 \pm 0.1$ & $2.661 \pm 0.1$ & $6.393 \pm 0.0$ & $6.011 \pm 1.0$ & 1.37 & increase \\
$\mathrm{A}_{3}$ & $14.874 \pm 0.2$ & $7.596 \pm 0.3$ & $2.785 \pm 0.1$ & $2.791 \pm 1.1$ & 0.19 & decrease \\
$\sum \mathrm{A}_{\mathrm{i}}$ & 36.492 & 15.795 & 14.335 & 12.449 & 0.34 & - \\
$\mathrm{w}_{1}$ & $8.691 \pm 0.0$ & $34.950 \pm 3.1$ & $6.857 \pm 0.0$ & $8.500 \pm 0.2$ & 0.98 & nearly constant \\
$\mathrm{w}_{2}$ & $8.230 \pm 0.5$ & $7.190 \pm 0.1$ & $10.645 \pm 0.0$ & $10.212 \pm 0.3$ & 1.24 & increase \\
$\mathrm{w}_{3}$ & $17.356 \pm 0.0$ & $16.442 \pm 5.1$ & $29.004 \pm 0.4$ & $13.963 \pm 3.5$ & 0.80 & nearly constant \\
$\mathrm{Tc}_{1}$ & $77.095 \pm 0.1$ & $122.156 \pm 22.3$ & $108.58 \pm 0.1$ & $113.10 \pm 5.2$ & 1.47 & increase \\
$\mathrm{Tc}_{2}$ & $119.28 \pm 8.4$ & $122.20 \pm 0.0$ & $152.00 \pm 0.1$ & $169.52 \pm 0.4$ & 1.42 & increase \\
$\mathrm{Tc}_{3}$ & $106.13 \pm 0.2$ & $137.42 \pm 0.4$ & $124.80 \pm 2.46$ & $153.57 \pm 1.2$ & 1.45 & increase \\
$\mathrm{To}_{1}$ & $3.18 \times 10^{-12} \pm$ & $5.993 \pm 0.2$ & $14.800 \pm 0.3$ & $0.733 \pm 0.5$ & - & decrease \\
$\mathrm{To}_{2}$ & 0.1 & $0.181 \pm 0.0$ & $4.5 \times 10^{-12} \pm 0.0$ & $0.509 \pm 0.3$ & 0.64 & decrease \\
$\mathrm{To}_{3}$ & $0.790 \pm 0.0$ & $0.164 \pm 0.4$ & $8.5 \times 10^{-11} \pm 0.0$ & $0.770 \pm 0.0$ & 0.97 & nearly constant \\
$\mathrm{R}^{2}$ & 0.9981 & 0.9995 & 0.9997 & 0.99905 & - & - \\
\hline
\end{tabular}

Table 5. EMG fit parameters of the loss factor curves for fique fabric-reinforced epoxy composite as a function of aging at high temperature. The column named 'change' gives the ratio of values between the aged state at $170{ }^{\circ} \mathrm{C}, 240 \mathrm{~h}$, and the unaged state.

\section{Fique Fabric Reinforcing Epoxy Composite $\left({ }^{\circ} \mathrm{C}\right)$}

\begin{tabular}{cccccc}
\hline Aging Time & $\mathbf{0}$ & $\mathbf{1 2 0}$ & $\mathbf{2 4 0}$ & Changes & Trend with Aging \\
\hline $\mathrm{A}_{1}$ & $2.278 \pm 0.4$ & $4.226 \pm 0.0$ & $1.483 \pm 0.0$ & 0.65 & decrease \\
$\mathrm{A}_{2}$ & $8.013 \pm 1.0$ & $3.097 \pm 0.0$ & $1.408 \pm 0.0$ & 0.18 & decrease \\
$\mathrm{A}_{3}$ & $7.810 \pm 0.8$ & $5.220 \pm 0.0$ & $1.716 \pm 0.0$ & 0.22 & decrease \\
$\sum \mathrm{A}_{\mathrm{i}}$ & 18.101 & 12.543 & 4.607 & 0.25 & - \\
$\mathrm{w}_{1}$ & $5.877 \pm 2.6$ & $19.017 \pm 0.4$ & $7.175 \pm 0.2$ & 1.22 & increase \\
$\mathrm{w}_{2}$ & $8.253 \pm 0.4$ & $8.182 \pm 0.0$ & $11.475 \pm 0.4$ & 1.39 & increase \\
$\mathrm{w}_{3}$ & $12.715 \pm 0.3$ & $15.686 \pm 0.0$ & $1.984 \pm 0.0$ & 0.16 & decrease \\
$\mathrm{Tc}_{1}$ & $75.551 \pm 2.6$ & $80.883 \pm 0.7$ & $105.42 \pm 0.1$ & 1.40 & increase \\
$\mathrm{Tc}_{2}$ & $82.026 \pm 0.8$ & $111.46 \pm 0.0$ & $155.20 \pm 0.3$ & 1.89 & increase \\
$\mathrm{Tc}_{3}$ & $109.98 \pm 2.2$ & $148.97 \pm 0.1$ & $179.20 \pm 0.0$ & 1.63 & increase \\
$\mathrm{To}_{1}$ & $6.78 \times 10^{-11} \pm 2.6$ & $39.103 \pm 1.2$ & $4.65 \times 10^{-18} \pm 0.0$ & - & increase \\
$\mathrm{To}_{2}$ & $8.165 \pm 1.9$ & $3.56 \times 10^{-13} \pm 0.0$ & $2.35 \times 10^{-17} \pm 0.0$ & - & decrease \\
$\mathrm{To}_{3}$ & $0.647 \pm 2.2$ & $0.411 \pm 0.0$ & $4.15 \times 10^{-15} \pm 0.0$ & - & increase \\
$\mathrm{R}^{2}$ & 0.9995 & 0.9991 & 0.9544 & - & - \\
\hline
\end{tabular}

Based on Tables 4 and 5, as the molecular mobility increased, the area under the tan $\delta$ curve and the amplitude of $\tan \delta$ peak (Figure 11) increased. Higher $\tan \delta$ means better damping (dissipation of energy) ability. Hence, if a structure that needs to absorb more dynamic energy is desired, the area under the tan $\delta$ curve should be increased. Regarding the amplitudes of tan $\delta$ curves in Figure 11, the results support that high-temperature aging has lower $\tan \delta$ peaks, which means a worse damping capability. In polymer composites, the fiber reinforcement and the interfacial interaction influence the damping factor, which provides a synergy effect between viscous and elastic phases in the material. Comparing the values obtained for the fique fabric composite and the plain epoxy, it can be observed that the lower $\tan \delta$ of the composite reflects good load-bearing properties of the system.

Similar behavior of peak 2 was found for the fique fabric-reinforced epoxy composite in comparison to plain epoxy. In both situations, what could have occurred what the literature reports as a diffusion-limited oxidation (DLO) phenomenon. The DLO facilitates the formation of a heterogeneous oxidized layer such that the regions near the air-exposed 
surfaces are heavily oxidized compared to the interior regions, which show reduced or minimal oxidation [41]. In summary, the DLO of polymers is the combination of two processes: (1) diffusion of oxygen and (2) reaction of oxygen. Atmospheric oxygen diffuses into the porous network of a polymeric material through its exposed surfaces, and the diffused oxygen reacts to form an oxide compound. DLO is more critical at elevated temperatures because the rate has higher activation energies than the permeability. It is worth mentioning that Pei et al. [42] also observed a double transition for the unaged control group, where the first peak was related to the glass-rubber transition of the material interior, and the second, the material exterior. The quantification of the effects, interaction, and amount of each aging time condition on the loss factor curve was possible using a model based on EMG distribution functions.

From these results it is proposed that the thermal degradation behavior of natural fibers, especially fique fiber, and their composites might be assessed, based on their structural characteristics and mechanical properties.

\section{Summary and Conclusions}

- Hemicellulose loss and oxidation are believed to be the main mechanisms for the microstructure changes that occur during thermal aging of fique fabric-reinforced epoxy composites. All samples of fique fabric, plain epoxy, and fique fabric composites revealed physical aspect changes at the macrostructural level, exhibiting a formation of a brownish layer at the sample surface.

- Mass loss rapidly increased at the initial stage of thermal aging, mainly due to the evaporation of moisture and the volatilization of residual low-molecular-weight substances. The samples thermally exposed for $120 \mathrm{~h}$ showed the higher mass loss, $\sim 14 \%$, and high shrinkage, $\sim 15 \%$, which might be associated with the outgassing of resin oxidation by-products.

- In DMA analyses, we observed significant property changes after aging. The most notable changes occurred in the storage modulus ( $\left.\mathrm{E}^{\prime}\right)$ curves. For samples aged for $72 \mathrm{~h}$, a significant decrease in $\mathrm{E}^{\prime}$ modulus was observed for both the plain epoxy and the fique fabric composite. In addition, an increase of $\mathrm{Tg}$ was observed for the samples aged up to $120 \mathrm{~h}$.

- By contrast, the fique fabric composite aged with 240-h aging time exhibited a lower $\mathrm{E}^{\prime}$ modulus, which indicated the degradation at the fiber-matrix interface, also verified in the SEM analyses.

- Additionally, it is worth mentioning the presence of a broad peak around $98^{\circ} \mathrm{C}$ for the unaged plain epoxy, which was attributed to the post-curing reaction given by the incomplete crosslinking.

- The loss factor results were modeled with three exponentially modified Gauss functions in order to get a molecular interpretation of the involved phenomena, which can be analyzed by the areas of the second and third transition peaks or the corresponding temperature values of the assigned Gauss peaks. The fique fabric composites presented smaller peak areas compared to the plain epoxy, which might be explained by the higher hindrance in mobility, an increase of stiffness, and an increase of crosslinking.

Author Contributions: Conceptualization, data curation, M.S.O., F.S.d.L. and S.N.M.; methodology, M.S.O. and V.d.O.A.; writing-original draft preparation, M.S.O. and F.S.d.L.; writing-review and editing, F.S.d.L., F.d.C.G.F., A.C.P. and S.N.M.; resources, H.A.C.L.; visualization, supervision, project administration, funding acquisition, S.N.M. All authors have read and agreed to the published version of the manuscript.

Funding: This research was partially financed by the Coordination for the Improvement of Higher Education Personal (CAPES), Brazil-Finance code 001, Carlos Filho Foundation for Research Support of the State of Rio de Janeiro (FAPERJ) process E26/202.286/2018, and the Brazilian National Council of Scientific Technological and Innovation Development (CNPq) grant number 423462/2018-0.

Institutional Review Board Statement: Not applicable. 
Informed Consent Statement: Not applicable.

Data Availability Statement: Not applicable.

Acknowledgments: The authors would like to thank the Brazilian agencies CNPq, CAPES, and FAPERJ (process E-26/202.286/2018) for their support.

Conflicts of Interest: The authors declare no conflict of interest.

\section{References}

1. Eaton, M.D.; Brinson, L.C.; Shull, K.R. Temperature dependent fracture behavior in model epoxy networks with nanoscale heterogeneity. Polymer 2021, 221, 123560. [CrossRef]

2. Henriques, I.R.; Borges, L.A.; Costa, M.F.; Soares, B.G.; Castello, D.A. Comparisons of complex modulus provided by different DMA. Polym. Test. 2018, 72, 394-406. [CrossRef]

3. Proia, A.; Matthys, S. Influence of environmental conditions on the glass transition temperature of epoxy used for strengthening applications. Polym. Test. 2019, 79, 106012. [CrossRef]

4. García-Moreno, I.; Caminero, M.; Rodríguez, G.; López-Cela, J. Effect of thermal ageing on the impact and flexural damage behaviour of carbon fibre-reinforced epoxy laminates. Polymers 2019, 11, 80. [CrossRef] [PubMed]

5. Park, J.; Osenbach, J. Processability and reliability of epoxy adhesive used in microelectronic devices linked to effects of degree of cure and damp heat aging. Microelectron. Reliab. 2006, 46, 503-511. [CrossRef]

6. Ma, X.; Guo, W.; Xu, Z.; Chen, S.; Cheng, J.; Zhang, J.; Miao, M.; Zhang, D. Synthesis of degradable hyperbranched epoxy resins with high tensile, elongation, modulus and low-temperature resistance. Compos. B Eng. 2020, 192, 108005. [CrossRef]

7. Lemos, M.F.; Bohn, M.A. DMA of polyester-based polyurethane elastomers for composite rocket propellants containing different energetic plasticizers. J. Therm. Anal. Calorim. 2016, 131, 595-600. [CrossRef]

8. Cerri, S.; Bohn, M.A.; Menke, K.; Galfetti, L. Aging of HTPB/Al/AP Rocket Propellant Formulations Investigated by DMA Measurements. Propellants Explos. Pyrotech. 2013, 38, 190-198. [CrossRef]

9. Lemos, M.F.; Mussbach, G.; Bohn, M.A. Evaluation of filler effects on the dynamic mechanical behavior of HTPB-elastomer used as binder in exemplary composite formulations. J. Aerosp. Technol. Manag. 2017, 9, 379-388. [CrossRef]

10. Oliveira, J.L.; Skilbred, A.W.B.; Loken, A.; Henriques, R.R.; Soares, B.G. Effect of accelerated ageing procedures and flash rust inhibitors on the anti-corrosive performance of epoxy coatings: EIS and dynamic-mechanical analysis. Prog. Org. Coat. 2021, 159, 106387. [CrossRef]

11. Peng, X.; Liu, Q.; Wang, D.; Liu, C.; Zhao, Y.; Wang, R.; Zheng, P. A hyperbranched structure formed by in-situ crosslinking of additive flame retardant endows epoxy resins with great flame retardancy improvement. Compos. B Eng. 2021, $224,109162$. [CrossRef]

12. Zhang, M.; Bareille, O.; Salvia, M. Cure and damage monitoring of flax fiber-reinforced epoxy composite repairs for civil engineering structures using embedded piezo micro-patches. Constr. Build. Mater. 2019, 225, 196-203. [CrossRef]

13. de Paula, A.C.; Uliana, F.; da Silva Filho, E.A.; Soares, K.; Luz, P.P. Use of DMA-Material Pocket to Determine the Glass Transition Temperature of Nitrocellulose Blends in Film Form. Carbohydr. Polym. 2019, 226, 115288.

14. Zheng, N.; Liu, H.-Y.; Gao, J.; Mai, Y.-W. Synergetic improvement of interlaminar fracture energy in carbon fiber/epoxy composites with nylon nanofiber/polycaprolactone blend interleaves. Compos. B Eng. 2019, 171, 320-328. [CrossRef]

15. Gobin, M.; Loulergue, P.; Audic, J.-L.; Lemiègre, L. Synthesis and characterisation of bio-based polyester materials from vegetable oil and short to long chain dicarboxylic acids. Ind. Crops. Prod. 2015, 70, 213-220. [CrossRef]

16. Karakaya, N.; Papila, M.; Özkoç, G. Effects of hot melt adhesives on the interfacial properties of overmolded hybrid structures of polyamide-6 on continuous carbon fiber/epoxy composites. Compos. A Appl. Sci. Manuf. 2020, 139, 106106. [CrossRef]

17. da Costa Garcia Filho, F.; da Luz, F.S.; Oliveira, M.S.; Pereira, A.C.; Costa, U.O.; Monteiro, S.N. Thermal behavior of graphene oxide-coated piassava fiber and their epoxy composites. J. Mater. Res. Technol. 2020, 9, 5343-5351. [CrossRef]

18. Dujardin, N.; Fois, M.; Grimau, M.; Poilâne, C. Soft interface dynamics in flax-fabrics/epoxy composites. Compos. Struct. 2018, 202, 389-396. [CrossRef]

19. da Luz, F.S.; Candido, V.S.; da Silva, A.C.R.; Monteiro, S.N. Thermal Behavior of Polyester Composites Reinforced with Green Sugarcane Bagasse Fiber. JOM 2018, 70, 1965-1971. [CrossRef]

20. Oliveira, M.S.; da Costa Garcia Filho, F.; da Luz, F.S.; da Cruz Demosthenes, L.C.; Pereira, A.C.; Colorado, H.A.; Nascimento, L.F.C.; Monteiro, S.N. Evaluation of Dynamic Mechanical Properties of Fique Fabric/Epoxy Composites. Mater. Res. $2019,22$. [CrossRef]

21. da Luz, F.S.; Monteiro, S.N.; Tommasini, F.J. Evaluation of Dynamic Mechanical Properties of PALF and Coir Fiber Reinforcing Epoxy Composites. Mater. Res. 2018, 21. [CrossRef]

22. Monteiro, S.N.; de Assis, F.S.; Ferreira, C.; Simonassi, N.T.; Weber, R.P.; Oliveira, M.S.; Colorado, H.; Pereira, A.C. Fique Fabric: A Promising Reinforcement for Polymer Composites. Polymers 2018, 10, 246. [CrossRef]

23. Wu, Y.; Xun, L.; Huang, S.; Ren, C.; Sun, B.; Gu, B. Crack spatial distributions and dynamic thermomechanical properties of 3D braided composites during thermal oxygen ageing. Compos. A Appl. Sci. Manuf. 2021, 144, 106355. [CrossRef]

24. Sánchez-Romate, X.F.; Sans, A.; Jiménez-Suárez, A.; Prolongo, S.G. The addition of graphene nanoplatelets into epoxy/polycaprolactone composites for autonomous self-healing activation by Joule's heating effect. Compos. Sci. Technol. 2021, 213, 108950. [CrossRef] 
25. Mayandi, K.; Rajini, N.; Ayrilmis, N.; Indira Devi, M.P.; Siengchin, S.; Mohammad, F.; Al-Lohedan, H.A. An overview of endurance and ageing performance under various environmental conditions of hybrid polymer composites. J. Mater. Res. Technol. 2020, 9, 15962-15988. [CrossRef]

26. Fejdyś, M.; Kucharska-Jastrząbek, A.; Kośla, K. Effect of Accelerated Ageing on the Ballistic Resistance of Hybrid Composite Armour with Advanced Ceramics and UHMWPE Fibers. Fibres Text. East. Eur. 2020, 28, 71-80. [CrossRef]

27. Raji, M.; Zari, N.; Bouhfid, R.; el Kacem Qaiss, A. Durability of composite materials during hydrothermal and environmental aging. In Durability and Life Prediction in Biocomposites, Fibre-Reinforced Composites and Hybrid Composites, 1st ed.; Jawaid, M., Thariq, M., Saba, N., Eds.; Woodhead: Serdang, Malaysia, 2019; Volume 1, pp. 83-119.

28. Monteiro, S.N.; Lopes, F.P.D.; Ferreira, A.S.; Nascimento, D.C.O. Natural-fiber polymer-matrix composites: Cheaper, tougher, and environmentally friendly. JOM 2009, 61, 17-22. [CrossRef]

29. Balla, V.K.; Kate, K.H.; Satyavolu, J.; Singh, P.; Tadimeti, J.G.D. Additive manufacturing of natural fiber reinforced polymer composites: Processing and prospects. Compos. B Eng. 2019, 174, 106956. [CrossRef]

30. Satyanarayana, K.G.; Arizaga, G.G.C.; Wypych, F. Biodegradable composites based on lignocellulosic fibers-An overview. Prog. Polym. Sci. 2009, 34, 982-1021. [CrossRef]

31. Odesanya, K.O.; Ahmad, R.; Jawaid, M.; Bingol, S.; Adebayo, G.O.; Wong, Y.H. Natural fibre-reinforced composite for ballistic applications: A review. J. Polym. Environ. 2021, 10, 1-18. [CrossRef]

32. Nurazzi, N.M.; Asyraf, M.R.M.; Khalina, A.; Abdullah, N.; Aisyah, H.A.; Rafiqah, S.; Sabaruddin, F.A.; Kamarudin, S.H.; Norrahim, M.N.F.; Ilyas, A.; et al. A review on natural fiber reinforced polymer composite for bullet proof and ballistic applications. Polymers 2021, 13, 646. [CrossRef]

33. Nayak, S.Y.; Sultan, M.T.H.; Shenoy, S.B.; Kini, C.R.; Samant, R.; Shah, A.U.M.; Amuthakkannan, P. Potential of natural fibers in composites for ballistic applications-A review. J. Nat. Fibers 2021, 44, 1-11. [CrossRef]

34. Gañan, P.; Mondragon, I. Surface modification on fique fibers: Effects on their physico-mechanical properties. Polym. Compos. 2002, 383, 94. [CrossRef]

35. Teles, M.C.A.; Altoé, G.R.; Netto, P.A.; Colorado, H.A.; Margem, F.M.; Monteiro, S.N. Fique fiber tensile elastic modulus dependence with diameter using the Weibull statistical analysis. Mater. Res. 2015, 18, 193-199. [CrossRef]

36. Netto, P.A.; Altoé, G.R.; Margem, F.M.; Braga, F.O.; Monteiro, S.N.; Margem, J.I. Correlation between the density and the diameter of fique fibers. Mater. Sci. Forum. 2016, 869, 377-383. [CrossRef]

37. Oliveira, M.S.; Garcia Filho, F.C.; Luz, F.S.; Pereira, A.C.; Demosthenes, L.C.C.; Nascimento, L.F.C.; Monteiro, S.N. Tensile properties of epoxy matrix reinforced with fique fabric. Mater. Sci. Forum. 2020, 1012, 14-19. [CrossRef]

38. Pereira, A.C.; Assis, F.S.; Garcia Filho, F.C.; Oliveira, M.S.; Lima, E.S.; Lopera, H.A.C.; Monteiro, S.N. Evaluation of the projectile's loss of energy in polyester composite reinforced with fique fiber and fabric. Mat. Res. 2019, 22 (Suppl. 1). [CrossRef]

39. Oliveira, M.S.; Garcia Filho, F.C.; Pereira, A.C.; Nunes, L.F.; Luz, F.S.; Braga, F.O.; Colorado, H.A.; Monteiro, S.N. Ballistic performance and statistical evaluation of multilayered armor with epoxy-fique fabric composites using the Weibull analysis J. Mater. Res. Technol. 2019, 8, 5899-5908. [CrossRef]

40. Oliveira, M.S.; Luz, F.S.; Lopera, H.A.C.; Nascimento, L.F.C.; Garcia Filho, F.C.; Monteiro, S.N. Energy absorption and limit velocity of epoxy composites incorporated with fique fabric as ballistic armor-A brief report. Polymers 2021, 13, 2727. [CrossRef] [PubMed]

41. Inamdar, A.; Yang, Y.-H.; Prisacaru, A.; Gromala, P.; Han, B. High temperature aging of epoxy-based molding compound and its effect on mechanical behavior of molded electronic package. Polym. Degrad. Stab. 2021, 188, 109572. [CrossRef]

42. Pei, Y.; Wang, K.; Zhan, M.; Xu, W.; Ding, X. Thermal-oxidative aging of DGEBA/EPN/LMPA epoxy system: Chemical structure and thermal-mechanical properties. Polym. Degrad. Stab. 2011, 96, 1179-1186. [CrossRef]

43. Hinkley, J.A.; Connell, J.W. Resin systems and chemistry: Degradation mechanisms and durability. In Long-Term Durability of Polymeric Matrix Composites; Springer: Boston, MA, USA, 2012; pp. 1-37. [CrossRef]

44. Ernault, E.; Richaud, E.; Fayolle, B. Origin of epoxies embrittlement during oxidative ageing. Polym. Test. 2017, 63, 448-454. [CrossRef]

45. Schoeppner, G.A.; Tandon, G.P.; Ripberger, E.R. Anisotropic oxidation and weight loss in PMR-15 composites. Compos. Part A Appl. Sci. Manuf. 2007, 38, 890-904. [CrossRef]

46. Azwa, Z.N.; Yousif, B.F. Characteristics of kenaf fibre/epoxy composites subjected to thermal degradation. Polym. Degrad. Stab. 2013, 98, 2752-2759. [CrossRef]

47. Ezekiel, N.; Ndazi, B.; Nyahumwa, C.; Karlsson, S. Effect of temperature and durations of heating on coir fibers. Ind. Crops. Prod. 2011, 33, 638-643. [CrossRef]

48. Ching, Y.C.; Gunathilake, T.U.; Ching, K.Y.; Chuah, C.H.; Sandu, V.; Singh, R.; Liou, N.-S. Effects of high temperature and ultraviolet radiation on polymer composites. In Durability and Life Prediction in Biocomposites, Fibre-Reinforced Composites and Hybrid Composites; Elsevier: Amsterdam, The Netherlands, 2019; pp. 407-426.

49. Yang, D.G.; Wan, F.F.; Shou, Z.Y.; van Driel, W.D.; Scholten, H.; Goumans, L.; Faria, R. Effect of high temperature aging on reliability of automotive electronics. Microelectron. Reliab. 2011, 51, 1938-1942. [CrossRef]

50. Behera, A.; Thawre, M.M.; Ballal, A. Hygrothermal aging effect on physical and mechanical properties of carbon fiber/epoxy cross-ply composite laminate. Mater. Today: Proc. 2020, 28, 940-943. [CrossRef] 
51. Dhakal, H.; Zhang, Z.; Richardson, M. Effect of water absorption on the mechanical properties of hemp fibre reinforced unsaturated polyester composites. Compos. Sci. Technol. 2007, 67, 1674-1683. [CrossRef]

52. Ugochukwu, S.; Ridzuan, M.J.M.; Abdul Majid, M.S.; Cheng, E.M.; Razlan, Z.M.; Marsi, N. Effect of thermal ageing on the scratch resistance of natural-fibre-reinforced epoxy composites. Compos. Struct. 2021, 261, 113586. [CrossRef]

53. Krauklis, A.; Echtermeyer, A. Mechanism of yellowing: Carbonyl formation during hygrothermal aging in a common amine epoxy. Polymers 2018, 10, 1017. [CrossRef]

54. Fan, W.; Li, J.; Zheng, Y.; Liu, T.; Tian, X.; Sun, R. Influence of thermo-oxidative aging on the thermal conductivity of carbon fiber fabric reinforced epoxy composites. Polym. Degrad. Stab. 2016, 123, 162-169. [CrossRef]

55. Margem, F.M.; Monteiro, S.N.; Bravo Neto, J.; Rodriguez, R.J.S.; Soares, B.G. The dynamic-mechanical behavior of epoxy matrix composites reinforced with ramie fibers. Matéria 2010, 15, 164-171. [CrossRef]

56. Rocha, M.L.; Leite, M.C.O.; Ferreira, E.P.C.; Melo, J.D.D.; Barbosa, A.P.C. Accelerated aging effects in composites used as repair for pipes in oil industry. Polym. Compos. 2021, 42, 5918-5929. [CrossRef]

57. Stark, W. Investigation of the curing behaviour of carbon fibre epoxy prepreg by Dynamic Mechanical Analysis DMA. Polym. Test. 2013, 32, 231-239. [CrossRef]

58. Kumar, D.S.; Shukla, M.J.; Mahato, K.K.; Rathore, D.K.; Prusty, R.K.; Ray, B.C. Effect of post-curing on thermal and mechanical behavior of GFRP composites. IOP Conf. Ser. Mater. Sci. Eng. 2015, 75, 012012. [CrossRef]

59. Chateauminois, A.; Vincent, L.; Chabert, B.; Soulier, J.P. Study of the interfacial degradation of a glass-epoxy composite during hygrothermal ageing using water diffusion measurements and dynamic mechanical thermal analysis. Polymer 1994, 35, 4766-4774. [CrossRef]

60. Cucos, A.; Budrugeac, P.; Miu, L.; Mitrea, S.; Sbarcea, G. Dynamic mechanical analysis (DMA) of new and historical parchments and leathers: Correlations with DSC and XRD. Thermochim. Acta 2011, 516, 19-28. [CrossRef] 